Federal Reserve Bank of Minneapolis

Research Department Staff Report 296

Revised May 2006

\title{
Modeling the Transition to a New Economy: Lessons from Two Technological Revolutions*
}

\author{
Andrew Atkeson \\ University of California, Los Angeles, \\ Federal Reserve Bank of Minneapolis, \\ and National Bureau of Economic Research \\ Patrick J. Kehoe \\ Federal Reserve Bank of Minneapolis, \\ University of Minnesota, \\ and National Bureau of Economic Research
}

\begin{abstract}
Many view the period after the Second Industrial Revolution as a paradigmatic example of a transition to a new economy following a technological revolution and conjecture that this historical experience is useful for understanding other transitions, including that after the Information Technology Revolution. We build a model of diffusion and growth to study transitions. We quantify the learning process in our model using data on the life cycle of U.S. manufacturing plants. This model accounts quantitatively for the productivity paradox, the slow diffusion of new technologies, and the ongoing investment in old technologies after the Second Industrial Revolution. The main lesson from our model for the Information Technology Revolution is that the nature of transition following a technological revolution depends on the historical context: transition and diffusion are slow only if agents have built up through learning a large amount of knowledge about old technologies before the transition begins.
\end{abstract}

${ }^{*}$ We thank Kathy Rolfe and Joan Gieseke for excellent editorial assistance and the National Science Foundation for research support. The views expressed herein are those of the authors and not necessarily those of the Federal Reserve Bank of Minneapolis or the Federal Reserve System. 
The period 1860-1900 is often called the Second Industrial Revolution because of the large number of technologies invented during that time. Historians argue that the Second Industrial Revolution launched a century-long period of rapid development of new manufacturing technologies based on electricity (Schurr et al. 1960, Rosenberg 1976, Devine 1983, and David 1990, 1991). This increase in the pace of technical change led eventually to a new economy, characterized by faster growth in manufacturing productivity, as measured by output per hour.

That particular transition to a new economy is viewed by many as paradigmatic of what happens after any major and sustained increase in the pace of technical change. The transition has three main features: a productivity paradox, a surprisingly long delay between the increase in the pace of technical change and the increase in the growth rate of measured productivity; slow diffusion of new technologies; and continued investment in old technologies. David (1990) and Jovanovic and Rousseau (2005) have argued that all three of these features of the transition after the Second Industrial Revolution have parallels in the transition after the more recent Information Technology Revolution.

Why did the transition after the Second Industrial Revolution have these features? And are they likely to be seen in other such transitions? Here we attempt to answer those questions by building a model of technology diffusion and growth that is intended to capture the main elements of the historians' hypotheses about the technological constraints facing manufacturing plants that are thought to have shaped the transition to a new economy after the Second Industrial Revolution. These are that new technologies are embodied in plants, so that plants must be redesigned in order to use the new technologies; that improvements in the technologies for new plants are ongoing; and that new plants require a period of learning in order to use the new technologies. (See, for example, Schurr et al. 1960, Rosenberg 1976, Devine 1983, and David 1990, 1991.) We use this model to investigate what aspects of these technological constraints are critical quantitatively for generating this transition's three main features. We then use the model to ask what lessons can be learned from the transition after the Second Industrial Revolution to guide research on the Information Technology Revolution.

One lesson is that learning about each new embodied technology must be both substantial and protracted if the model is to reproduce the main features of the transition after 
the Second Industrial Revolution: a productivity paradox, a slow and S-shaped diffusion curve for new embodied technologies, and substantial ongoing investment in old technologies.

Our model generates a productivity paradox only if at the start of the transition agents have built up through learning a large stock of knowledge about old embodied technologies. This happens in our model if the learning process in the old economy is substantial and protracted relative to the pace of technical change for new embodied technologies. In this case, agents find it worthwhile to spend a long time learning about an existing technology before abandoning it in favor of a new embodied technology.

By the same logic, learning and built-up knowledge are critical for generating a slow diffusion of new technologies. Our model generates S-shaped diffusion curves from heterogeneity across plants in built-up knowledge about old technologies: plants with little built-up knowledge adopt the new technology sooner, while plants with a lot of built-up knowledge adopt the new technology later.

Finally, when learning is substantial and protracted, our model also generates ongoing investment in old technologies even after new technologies are introduced. This ongoing investment occurs because existing plants embodying old technologies continue to learn and thus grow by adding physical capital and labor for quite some time after new technologies are introduced.

One of our main contributions in making the model quantitative is to use micro data on the life cycle patterns of plants in the U.S. economy - their birth, growth, and death - to infer the parameters of the learning process at the plant level. Our method here builds on the work of Hopenhayn and Rogerson (1993) and Atkeson and Kehoe (2005). From these micro data on manufacturing plants, we discover that the learning process at the plant level is substantial and protracted. Indeed, we find that this learning continues for at least 20 years.

When the parameters of our model are set using our method for inferring learning, the model's predictions match the three main features of the transition after the Second Industrial Revolution surprisingly well. We find it intriguing that the model matches these data so well even though we did not attempt to replicate any features of the transition after the Second Industrial Revolution when we chose the parameters of our model. 
Our method of measuring learning at the plant level contrasts sharply with the standard approach in the learning literature, exemplified by the work of Bahk and Gort (1993). These researchers associate learning in a plant with changes in the average productivity of labor and capital at that plant as the plant ages. This method leads to the conclusion that there is very little learning at the plant level and, hence, if used with our model would predict fast transitions, fast diffusion of new technologies, and little or no ongoing investment in old technologies.

We argue in favor of our method of measuring learning because, in the context of our model, the method proposed by Bahk and Gort (1993) is conceptually flawed. Indeed, if it were applied to our model, it would find no learning at all, regardless of how much learning was actually going on. Our method for measuring learning is one of the features that distinguish our work from related models of transition based on embodiment and learning, including those of Hornstein and Krusell (1996) and Greenwood and Yorukoglu (1997).

What lessons can be drawn from our model for the transition following the more recent Information Technology Revolution? We investigate this question by following the lead of David (1990), Bresnahan, Brynjolfsson, and Hitt (2002), and others who argued that information technologies are similar to electricity in that they open up new possibilities for organizing business practices within organizations and that these organizations need to be redesigned to make productive use of these new information technologies. Motivated by this work, we reinterpret our model as having business organizations rather than manufacturing plants as the basic units of production. We assume that each new business organization embodies a new set of business practices that represent the current frontier of such practices and then learns to become more productive with these practices over time.

The main lesson we draw is that our model's implications for the transition after a technological revolution depend on the historical context in which that revolution occurs. In particular, our model predicts a slow transition only if agents have accumulated through learning a large stock of built-up knowledge of old technologies before the transition begins. For the Second Industrial Revolution, we argue that agents did have a large stock of built-up knowledge about factories based on steam and waterpower. For the IT Revolution, our model will predict a slow transition only if at the start of that revolution agents had a large stock 
of built-up knowledge about business practices based on old information technologies.

We use the model to examine which factors determine the extent of built-up knowledge in equilibrium. We show that the faster the pace of technical change in the old economy, the smaller the extent of built-up knowledge, and hence the faster the transition after a technological revolution. We also show that the more protracted and substantial the learning process, the larger the extent of built-up knowledge and the slower the transition after a technological revolution.

Currently, there are little data on the extent of built-up knowledge about business practices in organizations at the start of the IT Revolution. Our model, however, suggests that the extent of built-up knowledge about business practices can be inferred from data on the diffusion and life cycle of business practices. To generate quantitatively a slow transition following the IT Revolution in our model, we must assume that the diffusion of business practices before that revolution was very slow and that the life cycle of these business practices was very prolonged. For example, for our model to generate a transition after the IT Revolution that is as slow as that after the Second Industrial Revolution, at the start of the IT Revolution over 50 percent of the workforce must be employed in organizations with business practices that are more than six decades old.

At the general level, the technology diffusion in our model is related to the theoretical literature on S-shaped diffusion curves, including the work of Jovanovic and Lach (1989) and Chari and Hopenhayn (1991). In contrast to these papers, we have neither spillovers of learning nor complementarities. Our model differs from most of the literature on diffusion in that it generates substantial ongoing investment in old technologies. (An important exception is Chari and Hopenhayn 1991.)

More recent theoretical work on diffusion after a major technical change includes that of Aghion and Howitt (1998), Helpman and Trajtenberg (1998), and Laitner and Stolyarov (2003). In this literature, often referred to as work on general purpose technologies, the diffusion of a major new technology is constrained by the need to develop complementary inputs for that technology. These explanations for the slow diffusion of new technologies do not account for substantial investment in old technologies following major technical change. 


\section{A Paradigmatic Transition to a New Economy}

Many historians view the transition to a new economy after the Second Industrial Revolution as a paradigmatic example of a transition to a new economy after a major and sustained increase in the pace of technical change. Here we document the three main features of this transition: a productivity paradox, slow diffusion of new technologies, and ongoing investment in old technologies.

Many of the technologies that had a profound impact on living standards in the 20th century were invented between 1860 and 1900. These technologies include electricity, the internal combustion engine, the production of petroleum and other chemicals, telephones and radios, and indoor plumbing. (For a description of technological inventions during this time, see the work of Gordon 2000a.) Although all of these inventions undoubtedly had a substantial economic impact, we follow Schurr et al. (1960, 1990), Rosenberg (1976), Devine (1983), and David $(1990,1991)$ and focus on the new technologies based on electricity. These historians have argued that this revolution launched a century-long period of rapid development of new technologies for manufacturing based on electricity (Devine 1990).

In Figure 1 we show there was a productivity paradox, or a substantial lag between the increased pace of technical change and the response of measured productivity growth. ${ }^{1}$ We have computed linear trends in annual output per hour in U.S. manufacturing for three periods: 1869-99, 1899-1929, and 1949-69. (We chose these periods to omit the Great Depression and World War II; data are from the U.S. Department of Commerce, 1973.) The trend growth rate of output per hour in the three periods increases gradually, from 1.6 percent to 2.6 percent to 3.3 percent. (We chose 1869 as the starting point because the early data are derived from the U.S. Census Bureau's censuses of manufacturing establishments, which have been taken every decade since that year. We focus on the subsequent 100-year period. Gordon (2000b) documents a similar gradual acceleration for the growth of output per hour for the U.S. economy as a whole.)

In documenting the slow diffusion of new technologies, we focus on the diffusion of electric power in manufacturing over the period 1869-1939. In Figure 2 we plot the percentages of mechanical power in U.S. manufacturing establishments that were derived from water, steam, and electricity during 1869-1939 (Devine 1983, Table 3). Before 1899, more 
than 95 percent of mechanical power was derived from water and steam. Between 1899 and 1929, electricity use gradually replaced water and steam, so that by 1929 , over 75 percent of mechanical power was electric. If we measure the diffusion of electricity in manufacturing starting in 1869, we see that it took 50 years for electricity to provide 50 percent of mechanical power. This measure of the speed of diffusion is sensitive to the choice of starting date. A measure of the speed of diffusion that is less sensitive to that choice is the time required for a technology to diffuse from 5 percent to 50 percent. For electricity in U.S. manufacturing, such diffusion took place over about 20 years, from 1899 to 1919.

In documenting the ongoing investment in old technologies, we focus on the ongoing growth of steam power over the period 1869-1939. Figure 2 shows that the percentage of mechanical power derived from steam increased from roughly 50 percent in 1869 to roughly 80 percent in 1899. Given that the total amount of mechanical power in U.S. manufacturing increased over this time period, these data imply that there was substantial net new investment in steam power for at least 30 years following the development of electric power. To put the diffusion paths of these three types of power in a longer-term perspective, recall that waterpower is an extremely old technology, while steam power started diffusing in the United States between 1800 and 1810 (Atack, Bateman, and Weiss 1980). During the period 18001899, waterpower slowly gave way to steam power, and only after that did electric power gradually replace both of these older technologies.

\section{A Model of Technology Diffusion}

Now we present our quantitative general equilibrium model of the diffusion of new technologies and the corresponding impact of these technologies on economic growth. We build in three assumptions meant to capture historians' hypotheses about the technological constraints faced by manufacturers during the transition after the Second Industrial Revolution. $^{2}$

- New plants embody new technologies. ${ }^{3}$ This assumption is motivated by the work of Devine $(1983,1990)$ and David $(1990,1991)$, who argue that manufacturing plants needed to be completely redesigned in order to make good use of the new technologies stemming from the development of electric power. 
- Improvements in the technology for new plants are ongoing. Specifically, we model the transition to a new economy after the Second Industrial Revolution as arising from a once-and-for-all increase in the rate of improvement in the frontier technology embodied in the design of new plants. This assumption captures the arguments of Schurr et al. (1960), Rosenberg (1976), Devine (1990), and Sonenblum (1990) that the process of improving efficiency through changes in factory design after the Second Industrial Revolution continued for decades, through at least the 1980s, and lay behind the new economy after this revolution.

- New plants improve their technology through a period of learning. This assumption is consistent with a broad body of work on learning as well as the discussions of David (1990, 1991) and Chandler (1992).

In describing our model formally below, we look to build in these assumptions in abstract terms so that, with a simple reinterpretation, the model can be applied to a variety of transition experiences. Here we interpret the elements of the model with an eye toward applying it to the transition following the Second Industrial Revolution. Later we discuss how to interpret the elements of the model to apply it to the transition following the Information Technology Revolution.

\subsection{The Basic Structure}

In the model, time is discrete and is denoted by periods $t=0,1, \ldots$ The economy has a continuum of size 1 of households. Households have preferences over consumption $c_{t}$ given by $\sum_{t=0}^{\infty} \beta^{t} \log \left(c_{t}\right)$, where $\beta$ is the discount factor. Each household consists of a worker and a manager, each of whom supplies one unit of labor inelastically. Households are also endowed with the initial stock of physical capital and ownership of the plants that exist in period 0. Given sequences of wages for workers, wages for managers, and intertemporal prices $\left\{w_{t}, w_{m t}, p_{t}\right\}_{t=0}^{\infty}$, initial capital holdings $k_{0}$, and an initial value $a_{0}$ of the plants that exist in period 0 , households choose sequences of consumption $\left\{c_{t}\right\}_{t=0}^{\infty}$ to maximize utility subject to the budget constraint

$$
\sum_{t=0}^{\infty} p_{t} c_{t} \leq \sum_{t=0}^{\infty} p_{t}\left(w_{t}+w_{m t}\right)+k_{0}+a_{0}
$$


Production in this economy is carried out in plants. In any period, a plant is characterized by its specific productivity $A$ and its age $s$. To operate, a plant uses one unit of a manager's time, physical capital, and (workers') labor as variable inputs. If a plant with specific productivity $A$ operates with one manager, physical capital $k$, and labor $l$, the plant produces output

$$
q=z A^{(1-\gamma \theta) / \theta} F(k, l)^{\gamma}
$$

where the function $F$ is linearly homogeneous of degree 1 and the parameter $\gamma \in(0,1)$. The technology parameter $z$ is common to all plants and grows at an exogenous rate. We call $z$ economy-wide productivity. Following Lucas (1978, p. 511), we call $\gamma$ the span of control parameter of the plant's manager. Here the parameter $\gamma$ may be interpreted as determining the degree of diminishing returns at the plant level. We refer to the pair $(A, s)$ as the plant's organization-specific capital, or simply its organization capital. This pair summarizes the built-up expertise, or knowledge, that distinguishes one organization from another. In (2), the exponent $(1-\gamma \theta) / \theta$ on $A$ is a convenient scaling of specific productivity.

Each plant produces a differentiated product, which a competitive firm aggregates to produce a homogeneous final good. Each plant chooses its price and inputs to maximize profits given the downward-sloping demand from the firm that produces final goods. The competitive final goods firm produces aggregate output according to

$$
y_{t}=\left[\sum_{s} \int_{A} q_{t}(A)^{\theta} \lambda_{t}(A, s)\right]^{1 / \theta},
$$

where $\lambda_{t}(A, s)$ denotes the measure of plants with organization capital $(A, s)$ that operate in $t$. The final goods firm has a static demand function $q_{t}(A)=p_{t}(A)^{-1 /(1-\theta)} y_{t}$. Note that we use a symmetry property of the equilibrium: independently of age, all operating plants with the same specific productivity $A$ choose the same output and set the same price. We also normalize the price of the final good to be 1 .

The timing of events in period $t$ is as follows. An owner's decision whether to operate a plant is made at the beginning of the period. Plants that do not operate produce nothing; the organization capital in these plants is lost permanently. Plants with organization capital $(A, s)$ that do operate, in contrast, hire a manager, capital $k_{t}$, and labor $l_{t}$ and produce output $q$ 
according to (2). At the end of the period, operating plants draw independent innovations (or shocks) $\epsilon$ to their specific productivity, with probabilities given by age-dependent distributions $\left\{\pi_{s}\right\}$. Thus, a plant with organization capital $(A, s)$ that operates in period $t$ has stochastic organization capital $(A \epsilon, s+1)$ at the beginning of period $t+1$.

Consider the process by which a new plant enters the economy. Before a new plant can enter in period $t$, a manager must spend period $t-1$ preparing and adopting a blueprint for constructing the plant that determines the plant's initial specific productivity $\tau_{t}$. Blueprints adopted in period $t-1$ embody the frontier of knowledge (or frontier blueprint) regarding the design of plants at that point in time. This frontier evolves exogenously, according to the sequence $\left\{\tau_{t}\right\}_{t=0}^{\infty}$. Thus, a plant built in $t-1$ starts period $t$ with initial specific productivity $\tau_{t}$ and organization capital $(A, s)=\left(\tau_{t}, 0\right)$. Because this level of productivity is built into the plant at its start, we refer to growth in $\tau_{t}$ as embodied technical change.

We assume that capital and labor are freely mobile across plants in each period. Thus, for any plant that operates in period $t$, the decision of how much capital and labor to hire is static. Given a rental rate for capital $r_{t}$, a wage rate for labor $w_{t}$, and a managerial wage $w_{m t}$, the operating plant chooses employment of capital and labor to maximize variable profits

$$
d_{t}(A)=\max _{p, q, k, l} p q-r_{t} k-w_{t} l
$$

subject to (2) and the static demand function. Let $p_{t}(A), q_{t}(A), k_{t}(A)$, and $l_{t}(A)$ denote the solutions to this problem.

The decision whether to operate a plant is dynamic. This decision problem is described by the Bellman equation

$$
V_{t}(A, s)=\max \left[0, d_{t}(A)-w_{m t}+\frac{p_{t+1}}{p_{t}} \int_{\epsilon} V_{t+1}(A \epsilon, s+1) \pi_{s+1}(d \epsilon)\right],
$$

where the sequences $\left\{\tau_{t}, w_{t}, r_{t}, w_{m t}, p_{t}\right\}_{t=0}^{\infty}$ are given. The value $V_{t}(A, s)$ is the expected discounted stream of returns to the owner of a plant with organization capital $(A, s)$. This value is the maximum of the returns from closing the plant and those from operating it. The second term in the brackets on the right side of (4) is the expected discounted value of operating a plant of type $(A, s)$. It consists of current returns $d_{t}(A)-w_{m t}$ and the discounted 
value of expected future returns $V_{t+1}(A, s)$. The plant operates only if the expected returns from operating it are nonnegative.

An owner's decision whether to hire a manager to prepare a blueprint for a new plant is also dynamic. In period $t$, this decision is determined by the equation $V_{t}^{0}=-w_{m t}+$ $p_{t+1} V_{t+1}\left(\tau_{t+1}, 0\right) / p_{t}$. The value $V_{t}^{0}$ is the expected stream of returns to the owner of a new plant, net of the initial fixed cost $w_{m t}$ of paying a manager to prepare the blueprint for the plant. Managers are hired to prepare blueprints for new plants only if $V_{t}^{0} \geq 0$. Since there is free entry into the activity of starting new plants, in equilibrium we require that $V_{t}^{0} \phi_{t}=0$, where $\phi_{t}$ is the measure of managers starting new plants.

Let $k_{t}$ denote the aggregate physical capital stock. Then the resource constraints for physical capital and labor are $\sum_{s} \int_{A} k_{t}(A) \lambda_{t}(d A, s)=k_{t}$ and $\sum_{s} \int_{A} l_{t}(A) \lambda_{t}(d A, s)=1$. The resource constraint for aggregate output is $c_{t}+k_{t+1}=y_{t}+(1-\delta) k_{t}$, where $\delta$ is the depreciation rate of capital. The resource constraint for managers is $\phi_{t}+\sum_{s} \int_{A} \lambda_{t}(d A, s)=1$.

An equilibrium is defined in the obvious way. In this equilibrium, in each period $t$, the decision to operate a plant is summarized by an age-dependent cutoff rule $A_{t}^{*}(s)$. In period $t$, plants of age $s$ with specific productivity $A \geq A_{t}^{*}(s)$ continue operating, and those with $A<A_{t}^{*}(s)$ close.

To get a sense of the process for the birth, growth, and death - or the life cycle - of plants that our model generates, consider Figure 3. Here we show the evolution of the specific productivity of two plants that both enter in period $t=1860$. Both of these plants start with productivity equal to that of the frontier blueprint in 1860, namely, $\tau_{1860}$. This frontier blueprint grows exogenously over time at a constant rate, as shown by the solid straight line labeled $\log \tau_{t}$. The two plants each experience random shocks to their plant-specific productivity drawn from age-dependent distributions $\pi_{s}$. Plant 1 is relatively lucky in that it draws especially favorable shocks to its specific productivity, and plant 2 is relatively unlucky.

In every period, each plant makes a decision whether to continue or to close, or exit. This decision is based on a comparison of the plant's current specific productivity $A_{t}$ and its future prospects for learning, determined by the age-dependent distributions $\pi_{s}$ relative to the alternative of exiting and starting a new plant with the current frontier blueprint. The age-dependent cutoff rule $A_{t}^{*}(s)$ summarizes the decision. Plant 1 has relatively high specific 
productivity; hence, it exits only after operating 30 years. Plant 2 has relatively low specific productivity and exits much sooner. After these plants exit, the manager of each plant starts a new plant with the current frontier blueprint and begins the process of building up specific productivity in the new plant. ${ }^{4}$

In our model, technologies embodied in plants diffuse throughout the economy as new plants embodying these technologies are born and grow. Figure 3 also illustrates the mechanics of this diffusion. In 1863, the manager of plant 2 decides to exit and start a new plant that embodies the frontier blueprint of 1864 and then begins to learn with that new technology. Likewise, in 1890 the manager of plant 1 decides to exit and start a new plant that embodies the frontier blueprint of 1891 and then begins to learn with that new technology. In this manner, new plants embodying new technologies gradually replace old ones. Since our model has many such plants, each with different shocks to specific productivity, this diffusion of new embodied technologies occurs smoothly over time.

Formally, we measure the diffusion of embodied technologies as follows. Let $l_{t, s}=$ $\int_{A}\left(l_{t}(A) / l_{t}\right) \lambda_{t}(d A, s)$ denote the fraction of labor employed in plants of age $s$, and let

$$
D_{t, t+k}=\sum_{s=0}^{k} l_{t, s}
$$

be the fraction of labor employed in plants of age $k$ and younger. We measure the diffusion in period $t+k$ of embodied technologies developed in period $t$ or later by $D_{t, t+k}$, which, in the model, is the fraction of labor employed in plants using technologies developed in period $t$ or later.

\subsection{Measuring the Learning Process}

In our model the process governing learning is a key determinant of the rate at which a new technology diffuses. In the model learning at the plant level is represented by shocks to the plant's specific productivity. We argue here that data on plant size can be used to measure these shocks. ${ }^{5}$ We then contrast our approach to measuring learning with the standard approach taken in the literature on learning. 


\section{A. The Link Between Plant Size and Plant-Specific Productivity}

Our model implies a tight link between plant size and plant-specific productivity. Given this link, we can use data on the relative size of plants to infer the actual pattern of productivity changes, or learning, at the plant level.

To see the link between plant size and productivity, consider the static problem of allocating a given amount of capital and labor across plants at a point in time. For a given distribution $\lambda_{t}$ of organization capital, it is convenient to define

$$
n_{t}(A)=\frac{A}{\bar{A}_{t}}
$$

as the size of a plant of type $(A, s)$ in period $t$, where $\bar{A}_{t}=\sum_{s} \int_{A} A \lambda_{t}(d A, s)$ is the aggregate of the specific productivities across all plants. The variable $n_{t}(A)$ measures the relative size of the plant in terms of its capital or labor, in that the equilibrium allocations are $k_{t}(A)=n_{t}(A) k_{t}$ and $l_{t}(A)=n_{t}(A) l_{t}$.

A similar result holds for cohorts of plants. To see this result, define the aggregate of

the specific productivities of a cohort of plants of age $s$ as $\bar{A}_{t, s}=\int_{A} A \lambda_{t}(d A, s)$. Note from (6) that $\bar{A}_{t, s} / \bar{A}_{t}=\int_{A} n_{t}(A) \lambda_{t}(d A, s)$. We then have the following proposition.

Proposition. The aggregate of specific productivities of plants of age s relative to that of all plants is equal to the share of total employment in those plants; that is, $\bar{A}_{t, s} / \bar{A}_{t}=l_{t, s}$, where $l_{t, s}=\int_{A} \frac{l_{t}(A)}{l_{t}} \lambda_{t}(d A, s)$.

Given this proposition, we can use the data on employment shares by cohorts, $l_{t, s}$, to infer the pattern of learning, as measured by $\bar{A}_{t, s} / \bar{A}_{t}$. The data show that employment in a cohort of plants grows substantially as the cohort ages. For example, in terms of the cross section, the 1988 panel of the U.S. Census Bureau's Longitudinal Research Database (LRD) shows that the employment share of plants rises at least for the first 20 years of a plant's life and that the employment share of a cohort of plants of age 20 is more than seven times that of the cohort of brand-new plants. ${ }^{6}$ In terms of the panel evidence, Jensen, McGuckin, and Stiroh (2001) show that the employment share of a cohort of plants starts small and grows steadily with age.

From the perspective of our model, the LRD data imply that the aggregate of specific productivities of a cohort of plants grows faster than aggregate productivity for at least 20 
years. Since in the data the employment share of a cohort of plants of age 20 is more than seven times that of brand-new plants, our model implies that plants that survive 20 years have, at that age, learned so much that they are not only much more productive than they were when they were first built, but also much more productive than plants brand-new in that 20th year. Thus, for a relatively long period of time, the ongoing innovations that occur within an operating plant are, on average, much larger than the innovations from the frontier technology. In this sense, 20-year-old plants are technologically superior to their contemporary brand-new plants.

Note that the link between the employment shares $l_{t, s}$ and relative productivities $\bar{A}_{t, s} / \bar{A}_{t}$ established in the proposition is derived from static first-order conditions equating the value marginal product across plants. These first-order conditions hold regardless of any changes or trends in overall employment $l_{t}$. Hence, the fact that the data show trends in manufacturing employment - increasing in the first part of the century and decreasing in the second part - has no bearing on our method of inferring learning from employment shares.

We use employment shares of plant cohorts to infer the amount of learning that plants experience as they age. We also use them to infer the speed of diffusion of new technologies as expressed in (5).

\section{B. A Contrast with the Literature on Learning}

We have argued that theory implies that learning manifests itself in the plant-specific, or organization-specific, component of productivity can be uncovered from data on the relative size of organizations. This approach is quite different from that followed in much of the literature on learning at the organizational level. (For a survey, see the 1990 work of Argote and Epple.) In that literature, learning is measured by data on the relationship between labor productivity at the organization level and the age or production experience of the organization. This literature identifies many instances of a very strong relationship between the labor productivity of a specific organization and its age or production experience.

We take a different approach for two reasons. One is that more comprehensive panel data sets on manufacturing plants do not reveal a strong systematic relationship between the labor productivity of these plants and their age. The other reason we take a different 
approach is that, in the context of models like ours, such a relationship has no bearing on the extent of learning.

In the data, a large dispersion in average productivity occurs across plants. However, average productivity does not seem to vary systematically with plant age. For example, Jensen, McGuckin, and Stiroh (2001) study a large panel of plants and find that once they include controls for labor quality and capital intensity, "surviving cohorts regardless of age or vintage show similar (labor) productivity levels" (p. 331). Bartelsman and Dhrymes (1998) find similar results. Bahk and Gort (1993) run regressions of plant productivity on plant experience. Using gross sales as their measure of plant output, they find an economically small positive relationship between plant productivity and plant age. In particular, their regressions imply that labor productivity grows at 15 percent over the first 15 years of a plant's life. To see that this growth is economically small, note that over this 15 -year period, the average surviving plant has employment and value added growing by roughly 500 percent. Moreover, even in Bahk and Gort's data there may be no relationship between plant productivity and age: when they use the theoretically preferred value-added measure rather than gross output as a proxy for output, they find little relation between productivity and age.

Next we show that, consistent with the data, our model implies there should be no systematic relation between the labor productivity of a plant and its age or production experience. The model has this implication regardless of the amount of learning assumed at the plant level. To show this, we imagine the results we would get if we applied Bahk and Gort's approach to measuring learning to data generated from our model. Specifically, Bahk and Gort run a regression of plant output on plant inputs and some measure of experience and interpret the coefficient on the experience variable as measuring the extent of learning. Unfortunately, this approach is valid only if the movement in plants' inputs is essentially unrelated to their specific productivity. Theory, however, predicts precisely the opposite, as the following example makes clear.

Consider running Bahk and Gort's regression in a simplified version of our model. In this simplified model, let all plants be competitive and make a homogeneous final good $(\theta=$ 1 ). Let the output in plant $i$ in period $t$ be given by the production function $q_{i t}=z_{t} A_{i t}^{1-\gamma} l_{i t}^{\gamma}$, so that relative employment in this plant is given by $l_{i t} / l_{t}=A_{i t} / A_{t}$, where $l_{t}=\sum_{i} l_{i t}$ is aggregate 
employment and $A_{t}=\sum_{i} A_{i t}$ is the aggregate of specific productivities of all plants. Hence, taking logs of the plant production function and substituting for $A_{i t}$ from $l_{i t} / l_{t}=A_{i t} / A_{t}$ gives that, in equilibrium,

$$
\log q_{i t}=\log \left[z_{t}\left(A_{t} / l_{t}\right)^{1-\gamma}\right]+\log l_{i t}
$$

We can use (7) to calculate the coefficients in the following regression, of the form used by Bahk and Gort:

$$
\log q_{i t}=\beta_{1 t}+\beta_{2} \log l_{i t}+\beta_{3} x_{i t}
$$

where $x_{i t}$ is some measure of the age or past production of the plant. This regression necessarily yields estimates of $\beta_{3}=0$ along with $\beta_{1 t}=\log \left[z_{t}\left(A_{t} / l_{t}\right)^{1-\gamma}\right]$ and $\beta_{2}=1$. Bahk and Gort's interpretation of $\beta_{3}=0$ would be that no learning takes place at the plant level regardless of how much specific productivity $A_{i t}$ rises with age.

Notice also that in the equilibrium of the model, (7) implies that labor productivity is given by $q_{i t} / l_{i t}=z_{t}\left(A_{t} / l_{t}\right)^{1-\gamma}$ and, hence, is constant across all plants, regardless of their specific productivity $A_{i t}$. This observation points to the key difference between the implications for learning by an individual and that of an organization, which can add variable factors. Individuals who learn increase their labor productivity. Organizations that learn grow by adding variable factors in order to keep their labor productivity constant (at least with Cobb-Douglas production). Hence, we argue that the key variable to look at to determine the amount of learning (that is, built-up knowledge or organization-specific capital) is not some measure of either labor or capital productivity, but rather some measure of relative size.

\subsection{Quantification}

To derive our model's quantitative implications for the main features of transition to a new economy, we need to set both the macro and the micro parameters. In the model, a period is a year.

\section{A. Macro Parameters}

The model's macro parameters are few and fairly standard to quantify. The growth rate of output per hour $g$ and the depreciation rate $\delta$ are chosen to reproduce data on the 
U.S. manufacturing sector since World War II. We set $g=3.3$ percent to match the growth of manufacturing output per hour in 1949-69. We let the plant level production function be $F(k, l)=k^{\alpha} l^{1-\alpha}$. Because of imperfect competition, the share of GDP paid to physical capital is given by $\theta \gamma \alpha$. We use data for 1959-99 obtained from the U.S. Department of Commerce's national income and product accounts to set $\theta \gamma \alpha=19.9$ percent and $\delta=5.5$ percent, based on methodology described in our earlier work (Atkeson and Kehoe 2005). We set the discount factor $\beta=0.993$, so that the steady-state interest rate $i$ defined by $1+i=(1+g) / \beta$ is 4.1 percent.

Now consider the parameter $\nu=\gamma \theta$. On the basis of the work of Basu and Fernald (1995), Basu (1996), and Basu and Kimball (1997), we choose $\theta=0.9$, which implies a markup of 11 percent and an elasticity of demand of 10. The span of control parameter $\gamma$ measures the degree of diminishing returns in variable factors at the plant level. Hundreds of studies have estimated production functions with micro data. These analyses incorporate a wide variety of assumptions about the form of the production technology and draw on crosssectional, panel, and time-series data from virtually every industry and developed country. Douglas (1948) and Walters (1963) survey many studies. More recent work along these lines has also been done by Baily, Hulten, and Campbell (1992), Bahk and Gort (1993), Olley and Pakes (1996), and Bartelsman and Dhrymes (1998). This work finds that the returns to scale in production are fairly close to 1.0, with many of the estimates falling in the range from 0.9 to 1.0 . We choose $\gamma=0.95$. This makes $\nu=0.85$. This value of $\nu$ is consistent with the discussion of Atkeson, Khan, and Ohanian (1996). As we report later (in section 3.1), we did some sensitivity analysis with respect to $\gamma$ and found that with $\gamma=0.9$ and $\gamma=1.0$, we get very similar results.

\section{B. Micro Parameters}

We use the method described in our 2005 work to set the micro parameters governing plant-specific productivity. We rewrite the model so that the problem of choosing the learning parameters governing plant-specific productivity is equivalent to directly choosing parameters governing shocks to size. We assume that the shocks to size have a lognormal distribution, so

that $\log \epsilon_{s} \sim N\left(m_{s}, \sigma_{s}^{2}\right)$. We choose the means and standard deviations of these distributions 
to be smoothly declining functions of $s$. In particular, we set $m_{s}=\kappa_{1}+\kappa_{2}\left(\frac{S-s}{S}\right)^{2}$ for $s \leq S$ and $m_{s}=\kappa_{1}$ otherwise and $\sigma_{s}=\kappa_{3}+\kappa_{4}\left(\frac{S-s}{S}\right)^{2}$ for $s \leq S$ and $\sigma_{s}=\kappa_{3}$ otherwise. With this parameterization, the shocks for plants of age $S$ or older are drawn from a single distribution. Thus, shocks to plant size are parameterized by $\left\{\kappa_{i}\right\}_{i=1}^{4}$ and age $S$.

We choose the parameters governing these shocks so that the model matches data on the fraction of the labor force employed in plants of different age groups, as well as data on job creation and job destruction in plants of different age groups. We use these job statistics to set the means and variances of shocks to productivity. The data are from the 1988 panel of the U.S. Census Bureau's LRD, which has the most extensive breakdown of plants by age available.

More formally, we use the relevant statistics defined by Davis, Haltiwanger, and Schuh (1996): Employment in a plant in year $t$ is $\left(l_{t}+l_{t-1}\right) / 2$, where $l_{t}$ is the labor force in year $t$. Job creation in a plant in year $t$ is $l_{t}-l_{t-1}$ if $l_{t} \geq l_{t-1}$ and zero otherwise. Job destruction in a plant in year $t$ is $l_{t-1}-l_{t}$ if $l_{t} \leq l_{t-1}$ and zero otherwise. In Figure 4, we report for each age category these three statistics for U.S. manufacturing plants in 1988 for all plants in that category relative to the total employment in all plants. This gives us a total of 26 statistics from the data that we use to summarize the life cycle of plants.

We set the parameter $S=150$ and choose the four parameters $\left\{\kappa_{i}\right\}_{i=1}^{4}$ to minimize the sum of the squared errors between the corresponding 26 statistics computed from the model and those in the data. The resulting model statistics are also plotted in Figure 4 . The parameters that generate these shocks are $S=150, \kappa_{1}=-0.1829, \kappa_{2}=0.2520, \kappa_{3}=$ $\exp (-1.7289)$, and $\kappa_{4}=\exp (-7.0134)$.

In Figure 4A, we see that our model matches the employment shares fairly well. In Figures $4 \mathrm{~B}$ and $4 \mathrm{C}$, we see that our model implies a bit more job creation and job destruction on average than are observed in the data. To get some perspective on this, note that the implied statistics for the overall job creation and destruction rates are 8.3 percent and 8.4 percent for the data and are both 9.7 percent for the model. Note also that in annual data during 1972-93, the standard deviations of the overall job creation and job destruction rates are 2.0 and 2.7 percentage points. Together, then, these data reveal that the overall job creation and job destruction rates in our model are reasonably good estimates - within one 
standard deviation - of the time-series fluctuations in these rates observed in the data.

\section{The Transition After the Second Industrial Revolution}

Now we ask whether our quantitative model built to capture the historians' hypotheses about the constraints facing manufacturers in the Second Industrial Revolution can reproduce the main features of the transition after that revolution. To answer this question, we use the model to simulate a transition to a new economy with a permanently faster pace of technical change, driven by faster growth in the frontier blueprints for new plants. In this simulation, the faster growth assigned to the frontier blueprints is meant to capture the faster pace of technical change embodied in U.S. plant design after the development of electric power.

Our transition experiment is stark in that we assume that the transition to a new economy starts with a sudden, unanticipated, and permanent increase in the pace of embodied technical change. We make this assumption in order to give a stark picture of the transition dynamics implied by our model. We also view this assumption as in the spirit of the work of historians Devine (1983), David (1990), David and Wright (1999), and others

who document a substantial acceleration in the pace of technical change during the Second Industrial Revolution.

In this experiment, we find that the model reproduces the three main features of the transition after the Second Industrial Revolution very well. We follow that experiment with two others, designed to investigate whether or not the details of the learning process are key quantitatively in generating these results. We find that they are.

\subsection{The Transition Experiment}

We model the Second Industrial Revolution as a permanent increase in the pace of technical change. Specifically, consider an economy that is initially on a balanced growth path with steady growth in the frontier blueprints causing output per hour to grow 1.6 percent per year. This growth rate is the trend growth rate of output per hour in U.S. manufacturing for 1869-99. We denote this initial growth rate of the frontier blueprints by $g_{\tau}^{\text {old }}$. In our experiment, we suppose that at the beginning of the period labeled 1869, agents learn that the growth rate of the frontier blueprints increases once and for all, so that on the new balanced growth path, output per hour grows 3.3 percent per year (as in the U.S. data for 
1949-69), an increase of 1.7 percentage points. We denote this new growth rate of the frontier blueprints by $g_{\tau}^{\text {new }}$. We refer to these two balanced growth paths as the old economy and the new economy, respectively. We then compute the transition path of our model economy from the old economy to the new economy in response to this exogenous increase in the pace of embodied technical change.

In our experiment, we must set some initial conditions. We set the initial physical capital-output ratio and the distribution of organization capital across plants to be those from the balanced growth path of the old economy. In setting this initial distribution of organization capital, we assume that the distributions of the shocks to specific productivity are the same as those we used to match the U.S. micro data for 1988. Thus, in this experiment, the stochastic process for specific productivities is held fixed, whereas the growth rates of the frontier blueprints are varied. This amounts to assuming that the process of learning about any particular embodied technology does not depend on the rate at which new embodied technologies appear.

Now consider our model's implications for the three main features of the transition which we demonstrated in section 1: the productivity paradox, a slow diffusion of new technologies, and ongoing investment in old technologies.

Begin with the model's implications for the path of productivity, measured as output per hour. Figure 5 shows these implications for the period 1869-1969 together with the actual data for this period (as seen in Figure 1). The model clearly produces a productivity paradox. In the model, as in the data, the growth in output per hour gradually accelerates. Over the period 1869-99, the trend growth rate in output per hour is 1.6 percent in both the model and the data. Over the period 1899-1929, the trend growth rate in output per hour is 2.3 percent in the model and 2.6 percent in the data. In the model, as in the data, the growth rate in output per hour reaches its new steady state of 3.3 percent by 1940 .

A convenient summary measure of the speed of transition in our model is the number of years it takes for the growth rate of output per hour to rise by one percentage point relative to the growth rate of the old economy. Here it takes 50 years.

Next consider the model's implications for the diffusion of new technologies. Figure 6 shows this diffusion in the model and in the data during 1869-1939. For new technologies, we 
make the following comparison between model and data. For the model, we graph the percentage of output produced in plants with blueprints dated 1869 and later. This percentage is also the percentage of physical capital and labor employed in plants with these blueprints. For the data, we graph the percentage of total horsepower in U.S. manufacturing establishments provided by electric motors over the same period. In this comparison, we are assuming that in the data, plants that are driven by electric motors were built in and after 1869 and those driven by steam and water were built before 1869. With this interpretation, our model predicts a slow pace of diffusion of new technologies quite similar to that for electric motors in the data. In the model, technologies dated 1869 and later take 46 years to diffuse to 50 percent; in the data, electric motors take about 50 years.

Of course, in measuring diffusion rates, the choice of initial dates in the data is somewhat arbitrary. To make a comparison of diffusion rates in the model and the data that is not so dependent on initial dates, consider a statistic that is often used in the diffusion literature: the time it takes for diffusion to go from 5 percent to 50 percent. This time is roughly 20 years (1899-1919) for electric motors in the data; it is 19 years for new technologies in the model. Thus, either way we measure it, the diffusion in the model is similar to that in the data.

Note in Figure 6 that our model produces an S-shaped diffusion curve for new embodied technologies. It does so because of the heterogeneity across existing plants in the knowledge that they have built up about their old embodied technologies. Plants that have little such knowledge exit in favor of new plants early in the transition, while plants with substantial knowledge exit only later in the transition. That the diffusion curve is S-shaped is a quantitative result. The shape of this curve reflects the distribution of this knowledge across plants implied by the parameters of our learning process.

Finally, consider our model's implication for the extent of ongoing investment in old technologies. We have data on two old technologies, water and steam. So for the model, we consider two types of old technologies: those used in plants built before 1802, which we identify with waterpower, and those used in plants built between 1802 and 1869, which we identify with steam power. This dating of technologies in our model is consistent with the work of Atack, Bateman, and Weiss (1980). They suggest that the diffusion of steam power 
in the United States started sometime between 1800 and 1810. We choose to date steam as starting in 1802 so that our model is consistent with the data on the diffusion of steam power in 1869 . That is, in 1869, roughly 67 years after it began to diffuse, steam power accounts for 50 percent of output in the model and 50 percent of horsepower in the data.

In Figure 7, we graph our model's predictions for the percentages of output produced in plants using these old technologies from 1869 to 1939 implied by our dating scheme. We also reproduce the U.S. data seen earlier, in Figure 2, on the fractions of horsepower derived from water and steam power over this same time period. Clearly, in those data the fraction derived from waterpower declined steadily from 1869 to 1939, while the fraction of horsepower derived from steam initially increased from 50 percent to 80 percent from 1869 to 1899 and then declined. Our model reproduces both of these patterns very well.

These results imply that in the model there is considerable ongoing investment in old technologies for at least the first 30 years of the transition to a new economy. To understand this implication, note that in the model, by assumption, there are no new plants built using either of the old technologies during this time period. Hence, all of the increase in output accounted for by these old technologies is coming from existing plants that are growing larger by adding capital and labor. This growth is driven by continued learning about these old technologies.

Most of the parameters of our model are standard. The span of control parameter, $\gamma$, and the parameters of the learning process are less standard. Here we ask how sensitive are our results to these parameters? We first show that our results are not very sensitive to the choice of the span of control parameter. We then conduct experiments in the next subsection that show that they are sensitive to the choice of learning parameters.

Consider now the span of control parameter. We redid our transition experiments with $\gamma=.9$ and $\gamma=1.0$ so that $\nu=\gamma \theta$ equals .81 and .9 , respectively. (Recall that our initial values were $\gamma=.95$ and $\nu=.85$.) We found that these changes led to only slight differences in the speed of transition. For example, with $\gamma=.9$, the transition is slightly faster: it takes 45 years instead of 50 years for the growth rate of output to increase one percentage point and 41 years instead of 46 years for diffusion to reach 50 percent. With $\gamma=1$, the transition is slightly slower: it takes 61 years before the growth rate of output increases one percentage 
point and 58 years for diffusion to reach 50 percent.

\subsection{Learning Experiments}

Our model reproduces well the three main features of the transition to a new economy after the Second Industrial Revolution. We find this result remarkable given that the parameters of the learning process were not chosen to match any of these three features. With our approach to measuring learning, we find a learning process that is both substantial and protracted. Here we conduct two experiments to show that this finding is key quantitatively in generating our results. In our first experiment we consider a model in which, on average, there is no learning. In our second experiment we show that if we had used a learning process suggested by other researchers on the basis of an alternative method for measuring learning, our model does not reproduce the three main features of the transition.

In our first experiment, we set average learning to zero by setting the model's agedependent means of the shocks to plant-specific productivity to one (which with $A^{\prime}=A \varepsilon$, sets the expected growth rate of $A$ to zero). To get the transition to converge in this experiment, we increase the standard deviation of the productivity shocks by a factor of five. ${ }^{7}$ With these parameters, the model's features of the transition to the new economy are quite different from those seen after the Second Industrial Revolution. Productivity and diffusion move swiftly instead of slowly, and there is no ongoing investment in old technologies. It takes just five years for the growth rate of output per hour to increase by one percentage point and only four years for technologies dated 1869 and later to diffuse to 50 percent. In this experiment, with our dating scheme, the percentage of output produced using old technologies corresponding to steam (those dated 1802-69) starts at more than 99 percent at the beginning of the transition and falls to less than 1 percent in the next 30 years.

Recall that we follow Hopenhayn and Rogerson (1993) in using data on the size of U.S. manufacturing plants over their life cycle to infer the learning process. With this procedure, we find that learning is both substantial and protracted. Other researchers have not used these data to infer learning, but rather have inferred it by using regression estimates of the productivity of plants by age. (See, for example, the work of Jovanovic and Nyarko (1995),

Hornstein and Krusell (1996), Cooley, Greenwood, and Yorukoglu (1997), and Greenwood 
and Yorukoglu (1997), who rely on estimates of productivity at the plant level made by Bahk and Gort (1993).) As we have discussed above, there is not much evidence of a systematic relationship between plant age and plant productivity. Hence, it is not surprising that the learning processes used by these researchers imply that learning is much less substantial and protracted than our procedure implies.

In the second experiment, we consider the implications of our model for transition when plants have the learning process discussed by Cooley, Greenwood, and Yorukoglu (1997). We do so by setting the age-dependent means so that, on average, $A^{1-\nu}$ grows at 1 percent a year for the first 14 years and is then constant. (See the discussion of the Bahk-Gort learning process in the work of Cooley, Greenwood, and Yorukoglu (1997, p. 476)). Also, in order to get the transition to converge, we again increase the standard deviation of the productivity shocks by a factor of five. In this experiment, the model's transition to a new economy is also fast: it takes only eight years for the growth rate of output per hour to increase by one percentage point and only six years for technologies dated 1869 and later to diffuse to 50 percent. The percentage of output produced using old technologies corresponding to steam here also starts at more than 99 percent at the beginning of the transition and falls to less than 1 percent in the next 30 years.

The results of both of these experiments are consistent with the idea that the details of our particular learning process are primarily responsible for this particular model's ability to reproduce the main features of the transition to a new economy after the Second Industrial Revolution.

\section{Lessons for Other Technological Revolutions}

We have put forward an abstract model of transition that can be applied to a variety of technological revolutions. To apply our model to the transition after the Second Industrial Revolution, we used data on growth rates in the late 1800s to set initial conditions and data on manufacturing plants to set the parameters of the learning process. We found that our model with these initial conditions and this learning process could reproduce the transition after the Second Industrial Revolution remarkably well.

David $(1990,1991)$ argues that the transition after the Second Industrial Revolution 
serves as a useful paradigm for guiding research on the study of the transition following the Information Technology Revolution. Here we examine what lessons can be drawn from our model that might guide research into the similarities and differences between the transitions after these revolutions.

To begin we discuss how to reinterpret the elements of our model so that it might be applied to the IT Revolution. Here we follow David (1990), Bresnahan, Brynjolfsson, and Hitt (2002), Brynjolfsson, Hitt, and Yang (2002), and others in shifting our interpretation of the basic unit of production from a manufacturing plant to a business organization and our interpretation of blueprints from new manufacturing technologies based on electricity to new business practices based on information technology.

While there are clearly some qualitative parallels between the Second Industrial Revolution and the IT Revolution, there are also likely to be some quantitative differences that have important implications for the nature of transition. Specifically, our model predicts a slow transition only if agents have accumulated through learning a large stock of built-up knowledge of old technologies before the transition begins. For the Second Industrial Revolution we argue that agents did have a large stock of built-up knowledge about factories based on steam and waterpower. For the IT Revolution our model will predict a slow transition only if at the start of that revolution agents had a large stock of built-up knowledge about business practices based on old information technologies. In this sense, our model's main lesson for the transition after a technological revolution is that it depends on the historical context in which that revolution occurs.

We conduct two experiments with our model to examine which factors determine the extent of built-up knowledge in equilibrium. In the first experiment we show that the faster the pace of technical change in the old economy, the smaller the extent of built-up knowledge, and hence the faster the transition after a technological revolution. In the second experiment we show that the more protracted and substantial the learning process, the larger the extent of built-up knowledge and the slower the transition after a technological revolution.

Our experiments suggest that the extent to which the transition after the Second Industrial Revolution is a paradigm for the transition after the IT Revolution depends on the extent of knowledge about business practices that business organizations had built up prior 
to the IT Revolution. Currently there is little direct evidence on the extent of such built-up knowledge about business practices. Our model, however, does suggest data from which the extent of built-up knowledge about business practices might be measured. We finish the section with a discussion of these implications of our model for the measurement of built-up knowledge.

\subsection{Reinterpreting the Model}

Here we reinterpret our model for the IT Revolution. We shift the basic unit of production from a manufacturing plant to a business organization. We assume, then, that each new business organization starts with a set of business practices that embody the current frontier of such practices and then learns to become more productive with these practices over time. Specifically we reinterpret our three main technological assumptions as follows.

- New business organizations embody new business practices. This assumption is motivated by the work of Bresnahan, Brynjolfsson, and Hitt (2002) and Brynjolfsson, Hitt, and Yang (2002), who argue that the effective use of new information technology requires a redesign of the business organization.

- Improvements in the design of business organizations are ongoing. This assumption is motivated by the observation that increases in computing and networking capability have led to an increasing array of new types of business practices and is consistent with the observation of Scott Morton (1991).

- New organizations improve their practices through a period of learning. This assumption is consistent with the work of Brynjolfsson, Renshaw, and Van Alstyne (1997) and Brynjolfsson, Hitt, and Yang (2002), who argue that the process of improving an organization structure may involve a protracted period of learning before the payoffs from this investment are fully realized.

\subsection{The Transition Experiments}

We now conduct two experiments which demonstrate the importance of the stock of built-up knowledge for the speed of transition and how this stock varies with the model parameters. 


\section{A. A First Experiment}

We first demonstrate how our model's implications for the three main features of transition depend on the initial pace of technical change and hence the growth rate in the old economy. We then discuss that this relation between the pace of technical change in the old economy and the nature of the transition in our model arises because the stock of built-up knowledge varies with the pace of technical change.

In this experiment we conduct a series of simulations in which we vary the growth rate in the old economy, but hold fixed the assumption that growth is 1.7 percentage points higher in the new economy than in the old. Each time we hold fixed all other parameters of the model, including the learning parameters. Implicitly, here we are assuming that the learning process is the same one that we found for manufacturing plants.

We summarize the results of these simulations in Figure 8A. This figure shows the number of years that pass before the growth of measured productivity has risen by one percentage point, as well as the number of years until technologies that are new as of the start of the transition have diffused to 50 percent. Clearly, as the growth rate in the old economy increases, the extent of the productivity paradox decreases and new technologies diffuse more rapidly.

It is also the case that as the growth rate in the old economy increases, there is less ongoing investment in old technologies occurring during the transition to a new economy. Recall that after the Second Industrial Revolution, the percentage of output produced using old technologies corresponding to steam power rose from 50 percent to 80 percent in the first 30 years of the transition. Here, to make our analysis of old technologies parallel to that of steam after the Second Industrial Revolution, we report on the percentage of output produced using technologies that are up to 67 years old at the start of each simulated transition as well as the fraction of output produced using these same technologies 30 years later. When the initial growth rate is 1.5 percent, the percentage of output accounted for by old technologies rises from 42 percent to 78 percent in the first 30 years of transition. In contrast, when the initial growth rate is 3.5 percent, the percentage of output accounted for by old technologies falls from 97 percent to 1 percent in the first 30 years of transition.

Why does the model produce such different results for these transitions, when all 
that differs is the economy's initial growth rate? The answer lies in the extent of built-up knowledge that exists in the old economy. In the model, as we increase the initial growth rate, the diffusion rate of new technologies in the old economy also increases. Hence, the stock of built-up knowledge agents have about existing technologies in the old economy naturally decreases. With less built-up knowledge at the start of the transition, agents become more willing to abandon old technologies in favor of new ones.

In our model, the stock of built-up knowledge is characterized by the distribution of organization capital across productive units. A convenient aggregate measure of this stock of built-up knowledge, relative to the frontier blueprints, is $\left(\bar{A}_{t} / \tau_{t}\right)^{1-\nu}$. Note that the ratio $\bar{A}_{t} / \tau_{t}$ is the average of the specific productivity across productive units relative to the frontier blueprints available to new productive units. The exponent $1-\nu$ expresses this ratio in units of the Solow residual of a standard growth model.

How this ratio changes with growth rates can be demonstrated by the model. For example, in our transition experiment corresponding to the Second Industrial Revolution, this ratio was 2.23 in the old economy and only 1.25 in the new economy. Thus, builtup knowledge was nearly 80 percent higher in the old economy than in the new. In that transition, the initial growth rate in the old economy was 1.7 percent. In contrast, suppose that the initial growth rate had been 3.5 percent. Then, the model implies that these ratios would have been 1.17 in the old economy and 1.03 in the new economy, so that built-up knowledge would have been only 14 percent higher in the old economy than in the new.

More generally, Figure 8B shows the model's predictions for the stock of built-up knowledge in the old and new economies as a function of the growth rate in the old economy. Note that the stock of built-up knowledge in both economies falls as the growth rate in the old economy increases. Comparing Figures $8 \mathrm{~B}$ and $8 \mathrm{~A}$, then, we see the close link between the stock of built-up knowledge and the subsequent speed of transition.

\section{B. A Second Experiment}

Our first experiment indicates that our model does not produce a slow transition unless agents have a large amount of built-up knowledge about old technologies at the start of the transition and that there is not much built-up knowledge if the initial growth rate in the old 
economy is fast. We now show that in order to get a slow transition when the initial growth rate is high, we need learning to be much more substantial and protracted than we found from data on U.S. manufacturing plants.

Here we conduct a final transition experiment in which we increase the amount of learning in organizations by increasing the means of the idiosyncratic shocks to organizationspecific productivity by a constant factor independent of age. Recall that these shocks have a lognormal distribution, so that $\log \epsilon_{s} \sim N\left(m_{s}, \sigma_{s}^{2}\right)$. Specifically, we increase the mean of these shocks to $m_{s}^{\prime}=m_{s}+\Delta$ with $\Delta=.1133$.

With this change in the learning process, we conduct the following transition experiment. We suppose that the old economy starts with a relatively high growth rate of 3.3 percent and then agents suddenly learn that the growth of frontier blueprints has increased once and for all, so that the economy grows 5 percent per year on the new balanced growth path. The transition in this experiment is now very similar to the one we found after the Second Industrial Revolution: it takes 49 years for the growth rate of output per hour to rise one percentage point and 46 years for new technologies to diffuse to 50 percent. In terms of ongoing investment in old technologies, we find that technologies that are up to 67 years old account for 51 percent of output at the start of the transition and that these same technologies account for 81 percent of output 30 years later.

\section{Inferring the Extent of Built-Up Knowledge}

We have shown that in our model, the extent of built-up knowledge is critical for generating a slow transition and that this extent of built-up knowledge varies with the initial growth rate assumed in the old economy. While we cannot measure built-up knowledge directly, we can ask what variables in the model vary with the initial growth rate and how one might use these variables to infer the extent of built-up knowledge. Theory suggests that two variables in the old economy are particularly relevant: the diffusion of technologies and, depending on the application, either the life cycle of plants or the life cycle of business practices.

In our model, the speed of diffusion of technologies in the old economy increases with the initial growth rate. For example, in our simulations above, in the old economy technologies 
take 72 years to diffuse to 50 percent if the initial growth rate is 1.5 percent, whereas they take only 21 years if the initial growth rate is 3.5 percent. In our Second Industrial Revolution experiment, in the old economy technologies take 67 years to diffuse to 50 percent. As we discussed above, this slow diffusion of steam is consistent with the work of Atack, Bateman, and Weiss (1980), who suggest that steam took roughly 70 years to diffuse to 50 percent. In the context of our model, this slow diffusion implies that agents had built up a large stock of knowledge about old technologies prior to the Second Industrial Revolution.

In our model, the life cycle of plants in the old economy also varies with the initial growth rate. As the growth rate in the old economy increases, the fraction of the labor force employed in plants with older technologies shrinks and the fraction employed with the newest technology increases. For example, in our simulations above, in the old economy, when the initial growth rate is 1.5 percent, over 98 percent of the labor force is employed in plants at least 25 years old and only .02 percent is employed in plants using the newest technologies. In contrast, when the initial growth rate is 3.5 percent, 45 percent of the labor force is employed in plants at least 35 years old and 2.8 percent is employed in plants using the newest technologies. (In terms of entry and exit, note that the fraction employed with the newest technology is the employment-weighted rate, which, at least along a balanced growth path, is also the employment-weighted exit rate.)

In our second experiment, we demonstrated that our model could generate a slow transition starting from a high initial growth rate if learning is much more substantial and protracted than we found for U.S. manufacturing plants. To give a feel for the implications of the learning process we discussed above (where we increased the mean of these shocks by $\Delta=.0908$ ), in Figure 9 we show the distribution of employment across organizations of different ages implied by the model at the start of that transition. We see in this figure that employment is concentrated in organizations using very old business practices. Here 50 percent of employment is in organizations that use business practices that are at least 67 years old. Moreover, this learning process implies a very slow diffusion rate of new business practices: it takes 67 years for a new practice to diffuse to 50 percent.

These results indicate a final lesson from our model. If our model is to account for the slow transition following the Information Technology Revolution, then there must have been 
substantially more built-up knowledge about business practices within a given organization in the old economy preceding that revolution than there was about production processes within a given manufacturing plant that we measured from recent data. In the data this built-up knowledge would correspond to a life cycle of business practices that was much longer than the life cycle of U.S. manufacturing plants.

\section{Conclusion}

Many economists view the period after the Second Industrial Revolution as a paradigmatic example of a slow transition to a new economy following a technological revolution. We have presented a quantitative model of that transition that generates the three main features of that paradigm: a productivity paradox, slow diffusion of old technologies, and ongoing investment in old technologies after that revolution. We find that two features of the model are particularly important in generating this result: learning must be substantial and protracted, and built-up knowledge in the old economy must be large. We use data on the life cycle of plants to argue that learning about plant-specific technologies is indeed substantial and protracted. We point to the slow diffusion of steam before the Second Industrial Revolution

as indirect evidence consistent with the historians' claim that manufacturers had built up a large stock of knowledge with existing technologies before that revolution.

We are not able to apply the model in the same way to the effects of the more recent IT Revolution because of the lack of data needed to measure learning and built-up knowledge. But the model has given us some insight into how that transition may differ. Our experiments suggest that a transition to a new economy after a major, sustained increase in the pace of technical change will not always be slow, as it was after the Second Industrial Revolution. The speed of transition will depend on the existing rate of technical change. The transition will be fast when the pace of technical change is already quite fast.

Clearly, then, no simple analogy exists between the transition after the Second Industrial Revolution and the transition that we should expect after the Information Technology Revolution. Instead, the main lesson from our theory is that the nature of the transition after the Second Industrial Revolution depends in an important way on its historical context: it came at a time when the pace of embodied technical change was relatively slow. 
Of course, before any definitive analysis of the impact of the Information Technology Revolution can be fleshed out in a quantitative model such as ours, at least three issues must be addressed: Where are the new technologies embodied? How long is the period of learning after they are adopted? And how much built-up knowledge do existing organizations have with their current technologies? (See the work of Brynjolfsson and Hitt (2000) for some discussion of these questions.) With regard to information technologies, none of these questions are easy to answer quantitatively, but we have suggested how theory can be used to address these questions. 


\section{Notes}

${ }^{1}$ Throughout the study, we take as given the standard view expressed by historians (like David 1990) that there was in fact a sustained increase in the rate of technical change which began in the Second Industrial Revolution and continued for many decades afterward. This view, together with the data on manufacturing productivity, leads many observers to conclude that there was a productivity paradox after the Second Industrial Revolution. Our objective is to quantitatively assess whether our model of growth and technology diffusion can account for this productivity paradox as well as the associated diffusion patterns of new and old technologies. An alternative approach, which we do not take, is to argue that the historians are mistaken: the pace of technical change did not increase until several decades after the Second Industrial Revolution and, hence, there is no productivity paradox. An important issue such an approach would have to confront is how to generate the observed patterns of diffusion of new and old technologies.

${ }^{2}$ For a more detailed discussion of the links between the historical analyses and our model, see Atkeson and Kehoe (2001).

${ }^{3}$ Note that we do not assume that all new technologies are embodied in new plants. In fact, our model is consistent with the idea that most of the ongoing technical change in the economy is driven by either disembodied technical change or technical change embodied in other factors, such as capital goods or labor.

${ }^{4}$ Since our model has a fixed number of managers and each manager can either start a new plant or operate an existing plant, our assumptions imply that on a balanced growth path, the number of plants is fixed. An alternative assumption, pursued by Hopenhayn and Rogerson (1993), is that instead what is fixed is the cost in terms of consumption goods of starting a new plant. In that alternative model, the number of plants grows over time.

We have chosen our specification because it seems to be a good approximation to the data. Sands (1961) reports that over the period 1904-47, the number of manufacturing plants in the United States grew only 0.5 percent per year while output per manufacturing establishment grew nearly 3.0 percent per year. Clearly, most of the growth of output in this period came from more output from each plant and only a small part from an increase in the number of plants. 
${ }^{5}$ Our approach differs from that of a large literature which models specific productivity as endogenous. An advantage of our approach is that it allows us to match the process for productivity associated with learning directly to data on the growth process of plants. Moreover, at least in a steady state, we need not take a stand on whether this productivity is derived from active or passive learning, matching, or ongoing adoption of new technologies in existing plants. Outside of a steady state, however, we are implicitly assuming that the learning process does not vary with the growth rate of the economy.

${ }^{6}$ Here and throughout this study, our microeconomic data are taken from the U.S. Census Bureau's LRD on manufacturing plants. This data set is described in Davis, Haltiwanger, and Schuh (1996). We use data on employment, job creation, and job destruction from the 1988 panel of the LRD, which we obtained from John Haltiwanger's Web site, http://www.bsos.umd.edu/econ/haltiwanger.

${ }^{7}$ We need to increase the standard deviation in order to generate a smooth transition. If the standard deviation is too small, then the distribution of organization capital across plants becomes lumpy during the transition, and that introduces oscillatory dynamics. 


\section{References}

Aghion, Philippe, and Howitt, Peter. 1998. Endogenous growth theory. Cambridge, Mass.: MIT Press.

Argote, Linda, and Epple, Dennis. 1990. Learning curves in manufacturing. Science 247 (February): 920-24.

Atack, Jeremy; Bateman, Fred; and Weiss, Thomas. 1980. The regional diffusion and adoption of the steam engine in American manufacturing. Journal of Economic History 40 (June): 281-308.

Atkeson, Andrew, and Kehoe, Patrick J. 2001. The transition to a new economy after the Second Industrial Revolution. Working Paper 8676, National Bureau of Economic Research.

. 2005. Modeling and measuring organization capital. Journal of Political Economy 113 (October): 1026-53.

Atkeson, Andrew; Khan, Aubhik; and Ohanian, Lee. 1996. Are data on industry evolution and gross job turnover relevant for macroeconomics? Carnegie-Rochester Conference Series on Public Policy 44 (June): 215-50.

Bahk, Byong-Hyong, and Gort, Michael. 1993. Decomposing learning by doing in new plants. Journal of Political Economy 101 (August): 561-83.

Baily, Martin Neil; Hulten, Charles; and Campbell, David. 1992. Productivity dynamics in manufacturing plants. Brookings Papers on Economic Activity: Microeconomics: $187-249$.

Bartelsman, Eric J., and Dhrymes, Phoebus J. 1998. Productivity dynamics: U.S. manufacturing plants, 1972-1986. Journal of Productivity Analysis 9 (January): 5-34.

Basu, Susanto. 1996. Procyclical productivity: Increasing returns or cyclical utilization? Quarterly Journal of Economics 111 (August): 719-51.

Basu, Susanto, and Fernald, John G. 1995. Are apparent productive spillovers a figment of specification error? Journal of Monetary Economics 36 (August): 165-88.

Basu, Susanto, and Kimball, Miles S. 1997. Cyclical productivity with unobserved input variation. Working Paper 5915, National Bureau of Economic Research.

Bresnahan, Timothy F.; Brynjolfsson, Erik; and Hitt, Lorin M. 2002. Information technol- 
ogy, workplace organization, and the demand for skilled labor: Firm-level evidence. Quarterly Journal of Economics 117 (February): 339-76.

Brynjolfsson, Erik, and Hitt, Lorin M. 2000. Beyond computation: Information technology, organizational transformation and business performance. Journal of Economic Perspectives 14 (Fall): 23-48.

Brynjolfsson, Erik; Hitt, Lorin M.; and Yang, Shinkyu. 2002. Intangible assets: Computers and organizational capital. Brookings Papers on Economic Activity: 137-81.

Brynjolfsson, Erik; Renshaw, Amy Austin; and Van Alstyne, Marshall. 1997. The matrix of change: A tool for business process reengineering. Sloan Management Review (Winter): $37-54$.

Chandler, Alfred D. 1992. Organizational capabilities and the economic history of the industrial enterprise. Journal of Economic Perspectives 6 (Summer): 79-100.

Chari, V.V., and Hopenhayn, Hugo. 1991. Vintage human capital, growth, and the diffusion of new technology. Journal of Political Economy 99 (December): 1142-65.

Cooley, Thomas F.; Greenwood, Jeremy; and Yorukoglu, Mehmet. 1997. The replacement problem. Journal of Monetary Economics 40 (December): 457-99.

David, Paul A. 1990. The dynamo and the computer: An historical perspective on the modern productivity paradox. American Economic Review 80 (May): 355-61.

. 1991. Computer and dynamo: The modern productivity paradox in a not-toodistant mirror. In Technology and productivity: The challenge for economic policy, pp. 315-45. Paris: Organisation for Economic Co-operation and Development.

David, Paul A., and Wright, Gavin. 1999. General purpose technologies and surges in productivity: Historical reflections on the future of the ICT revolution. Department of Economics Working Paper 99-026, Stanford University.

Davis, Steven J.; Haltiwanger, John C.; and Schuh, Scott. 1996. Job creation and destruction. Cambridge, Mass.: MIT Press.

Devine, Warren D., Jr. 1983. From shafts to wires: Historical perspective on electrification. Journal of Economic History 43 (June): 347-72.

. 1990. Electricity in information management: The evolution of electronic control. In Sam H. Schurr, Calvin C. Burwell, Warren D. Devine, Jr., and Sidney So- 
nenblum, eds., Electricity in the American economy: Agent of technological progress. Westport, Conn.: Greenwood Press.

Douglas, Paul H. 1948. Are there laws of production? American Economic Review 38 (March): 1-41.

Gordon, Robert J. 2000a. Does the "new economy" measure up to the great inventions of the past? Journal of Economic Perspectives 14 (Fall): 49-74.

. 2000b. Interpreting the "one big wave" in U.S. long-term productivity growth. In Bart van Ark, Simon K. Kuipers, and Gerard H. Kuper, eds., Productivity, technology, and economic growth, pp. 19-65. Boston: Kluwer.

Greenwood, Jeremy, and Yorukoglu, Mehmet. 1997. 1974. Carnegie-Rochester Conference Series on Public Policy 46 (June): 49-95.

Helpman, Elhanan, and Trajtenberg, Manuel. 1998. Diffusion of general purpose technologies. In Elhanan Helpman, ed., General purpose technologies and economic growth, pp. 85-119. Cambridge, Mass.: MIT Press.

Hopenhayn, Hugo, and Rogerson, Richard. 1993. Job turnover and policy evaluation: A general equilibrium analysis. Journal of Political Economy 101 (October): 915-38.

Hornstein, Andreas, and Krusell, Per. 1996. Can technology improvements cause productivity slowdowns? In Ben S. Bernanke and Julio J. Rotemberg, eds., NBER Macroeconomics Annual 1996, vol. 11, pp. 209-59. Cambridge, Mass.: MIT Press.

Jensen, J. Bradford; McGuckin, Robert H.; and Stiroh, Kevin J. 2001. The impact of vintage and survival on productivity: Evidence from cohorts of U.S. manufacturing plants. Review of Economics and Statistics 83 (May): 323-32.

Jovanovic, Boyan, and Lach, Saul. 1989. Entry, exit, and diffusion with learning by doing. American Economic Review 79 (September): 690-99.

Jovanovic, Boyan, and Nyarko, Yaw. 1995. A Bayesian learning model fitted to a variety of empirical learning curves. Brookings Papers on Economic Activity: Microeconomics: $247-99$.

Jovanovic, Boyan, and Rousseau, Peter L. 2005. General purpose technologies. Working Paper 11093, National Bureau of Economic Research.

Laitner, John, and Stolyarov, Dmitriy L. 2003. Technological change and the stock market. 
American Economic Review 93 (September): 1240-67.

Lucas, Robert E., Jr. 1978. On the size distribution of business firms. Bell Journal of Economics 9 (Autumn): 508-23.

Olley, G. Steven, and Pakes, Ariel. 1996. The dynamics of productivity in the telecommunications equipment industry. Econometrica 64 (November): 1263-97.

Rosenberg, Nathan. 1976. On technological expectations. Economic Journal 86 (September): $523-35$.

Sands, Saul S. 1961. Changes in scale of production in United States manufacturing industry, 1904-1947. Review of Economics and Statistics 43 (November): 365-68.

Schurr, Sam H.; Burwell, Calvin C.; Devine, Warren D., Jr.; and Sonenblum, Sidney, eds. 1990. Electricity in the American economy: Agent of technological progress. Westport, Conn.: Greenwood Press.

Schurr, Sam H.; Netschert, Bruce C.; Eliasberg, Vera; Lerner, Joseph; and Landsberg, Hans H. 1960. Energy in the American economy, 1850-1975: An economic study of its history and prospects. Baltimore: Johns Hopkins University Press.

Scott Morton, Michael S., ed. 1991. The corporation of the 1990s: Information technology and organizational transformation. New York: Oxford University Press.

Sonenblum, Sidney. 1990. Electrification and productivity growth in manufacturing. In Sam H. Schurr, Calvin C. Burwell, Warren D. Devine, Jr., and Sidney Sonenblum, eds., Electricity in the American economy: Agent of technological progress. Westport, Conn.: Greenwood Press.

U.S. Department of Commerce, Bureau of Economic Analysis. 1973. Long-term economic growth, 1860-1970. Washington, D.C.: Bureau of Economic Analysis. . Various dates. National income and product accounts of the United States. Survey of Current Business. Available at http://www.bea.gov.

Walters, Alan A. 1963. Production and cost functions: An econometric survey. Econometrica 31 (January-April): 1-66. 


\section{Figures 1-2 A Gradual Transition to a New Economy}

\section{Figure 1 A Slow Increase in Productivity Growth ...}

Log of Output per Hour and Trend Growth in U.S. Manufacturing, 1869-1969

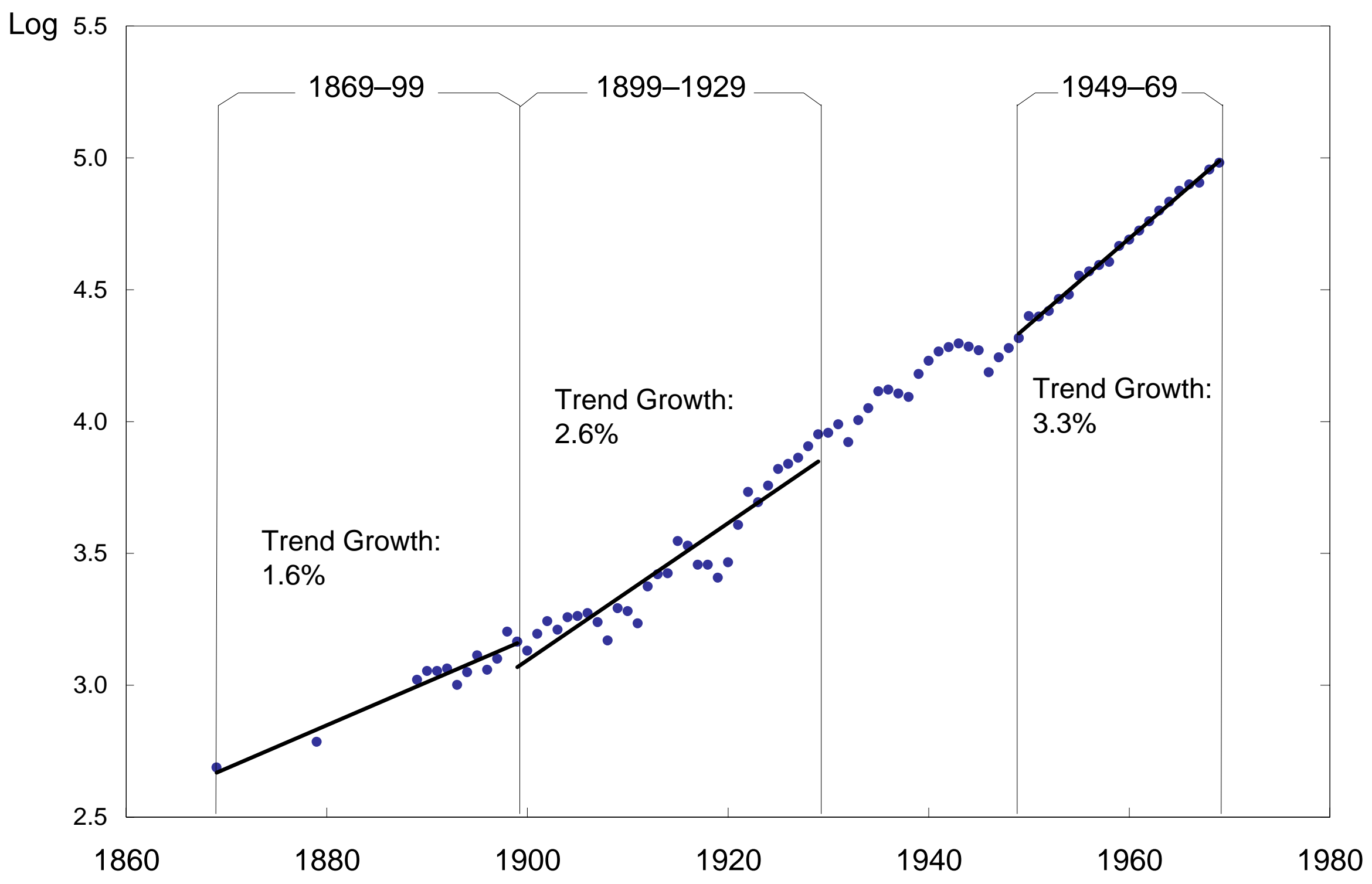

Source: U.S. Department of Commerce (1973) 


\section{Figure $2 \quad \ldots$ And Slow Diffusion of Electric Power}

Percentage of Total Horsepower from Three Sources of Mechanical Drive in U.S. Manufacturing, 1869-1939

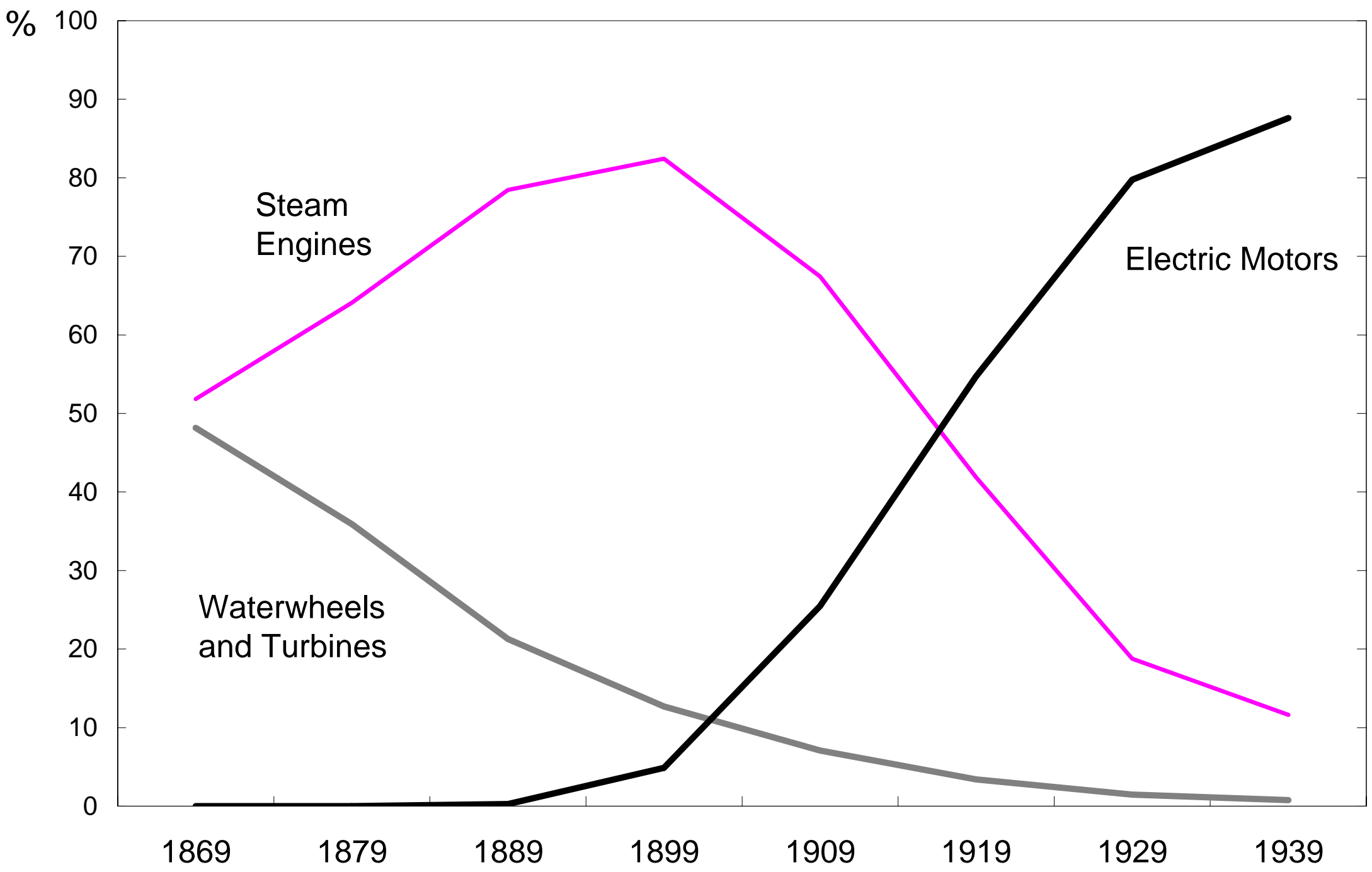

Source of data: Devine (1983, p. 351, Table 3) 
Figure 3 The Life Cycle of Plants in the Model

Productivity of Two Plants vs. That of Frontier Blueprint Over Time

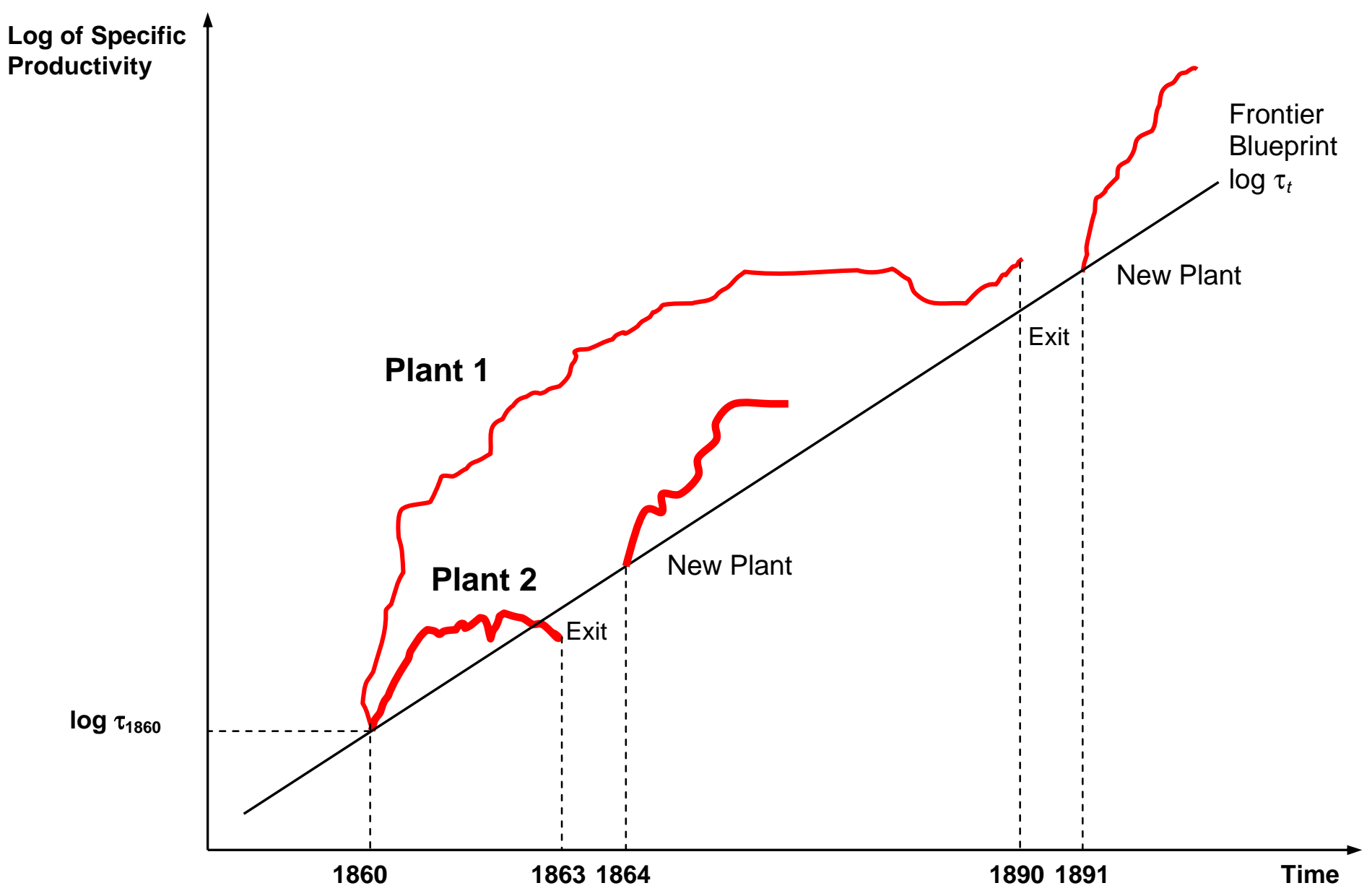


Figure 4 The Model's Reproduction of U.S. Data on Employment, Job Creation, and Job Destruction

Each Statistic as a Percentage of Total U.S. 1988 Employment for Manufacturing Plants of Various Ages

\section{- U.S. Data $\quad$ 目 Model}

\section{A. Employment}

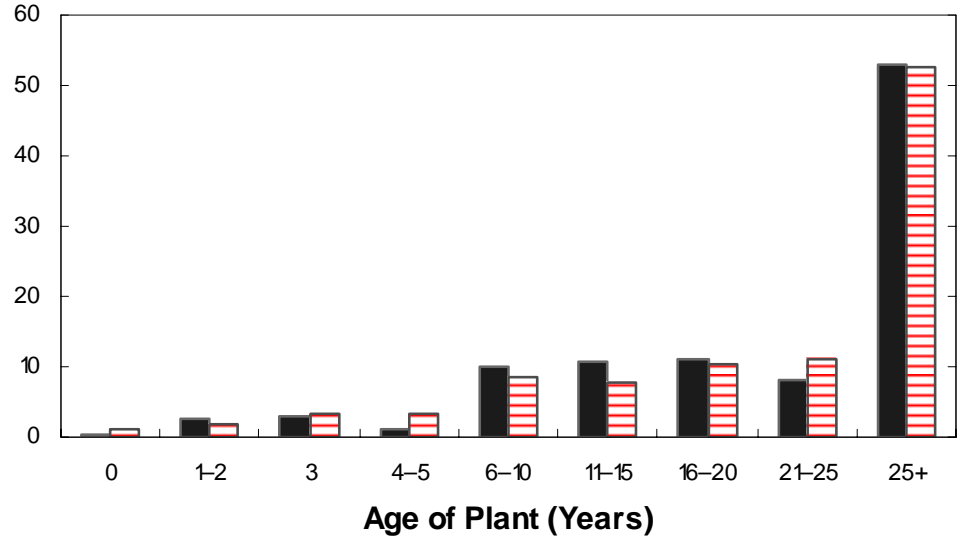

B. Job Creation

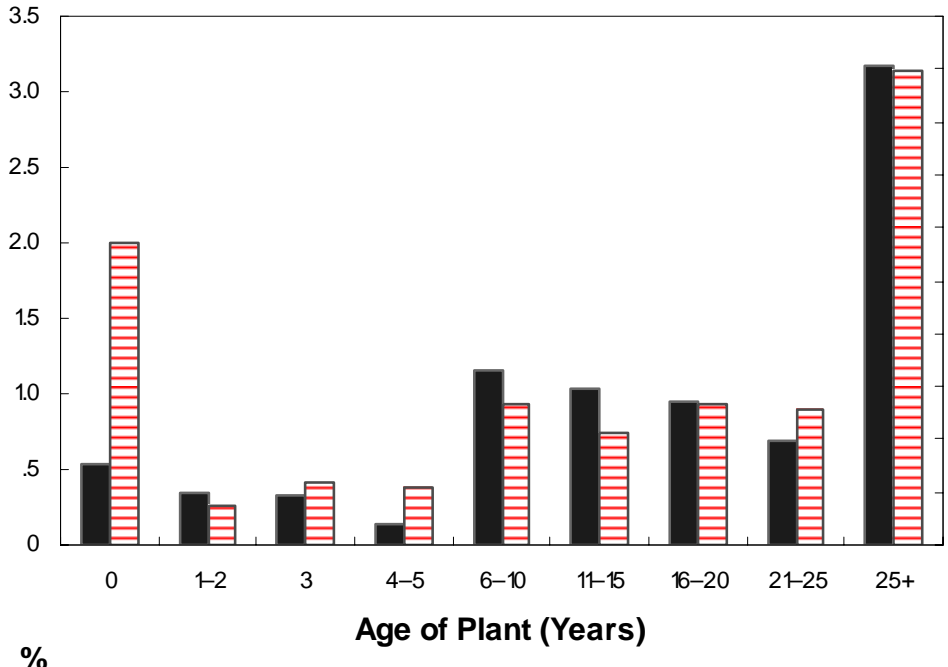

\begin{tabular}{ll}
\multicolumn{2}{c}{ All Plants 1988} \\
\hline Model & $9.7 \%$ \\
Data & $8.3 \%$ \\
S.D. & \\
1972-93 & $2.0 \%$ pts
\end{tabular}

\section{Job Destruction}

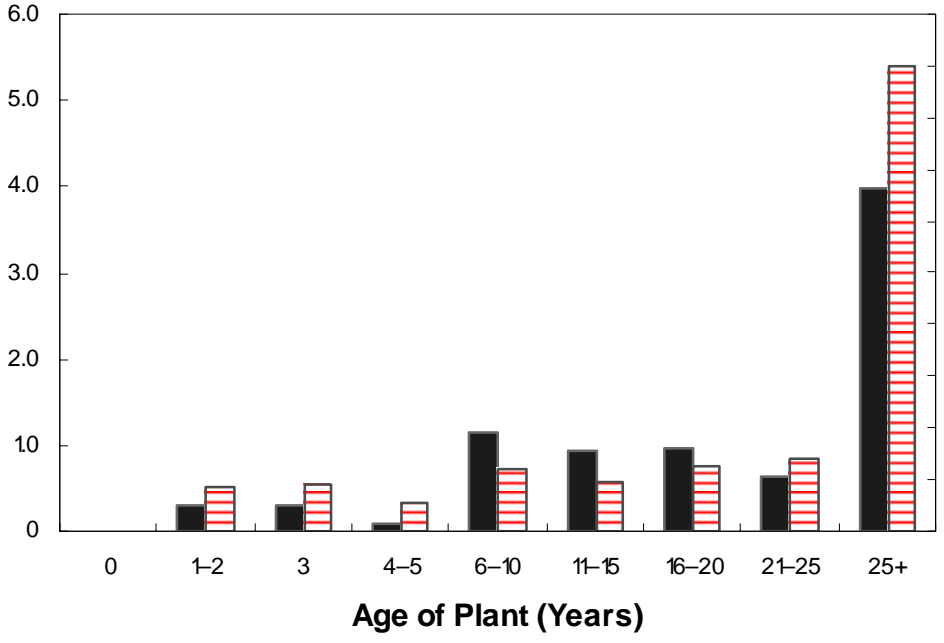

\begin{tabular}{ll}
\multicolumn{2}{c}{ All Plants 1988} \\
\hline Model & $9.7 \%$ \\
Data & $8.4 \%$ \\
S.D. & \\
1972-93 & $2.7 \%$ pts \\
\hline
\end{tabular}




\section{Figures 5-7 The Model's Reproduction of the Gradual Transition to a New Economy}

\section{Figure 5 A Slow Increase in Productivity Growth ...}

Log of Output per Hour and Trend Growth in Manufacturing, 1869-1969, in the Data and the Model

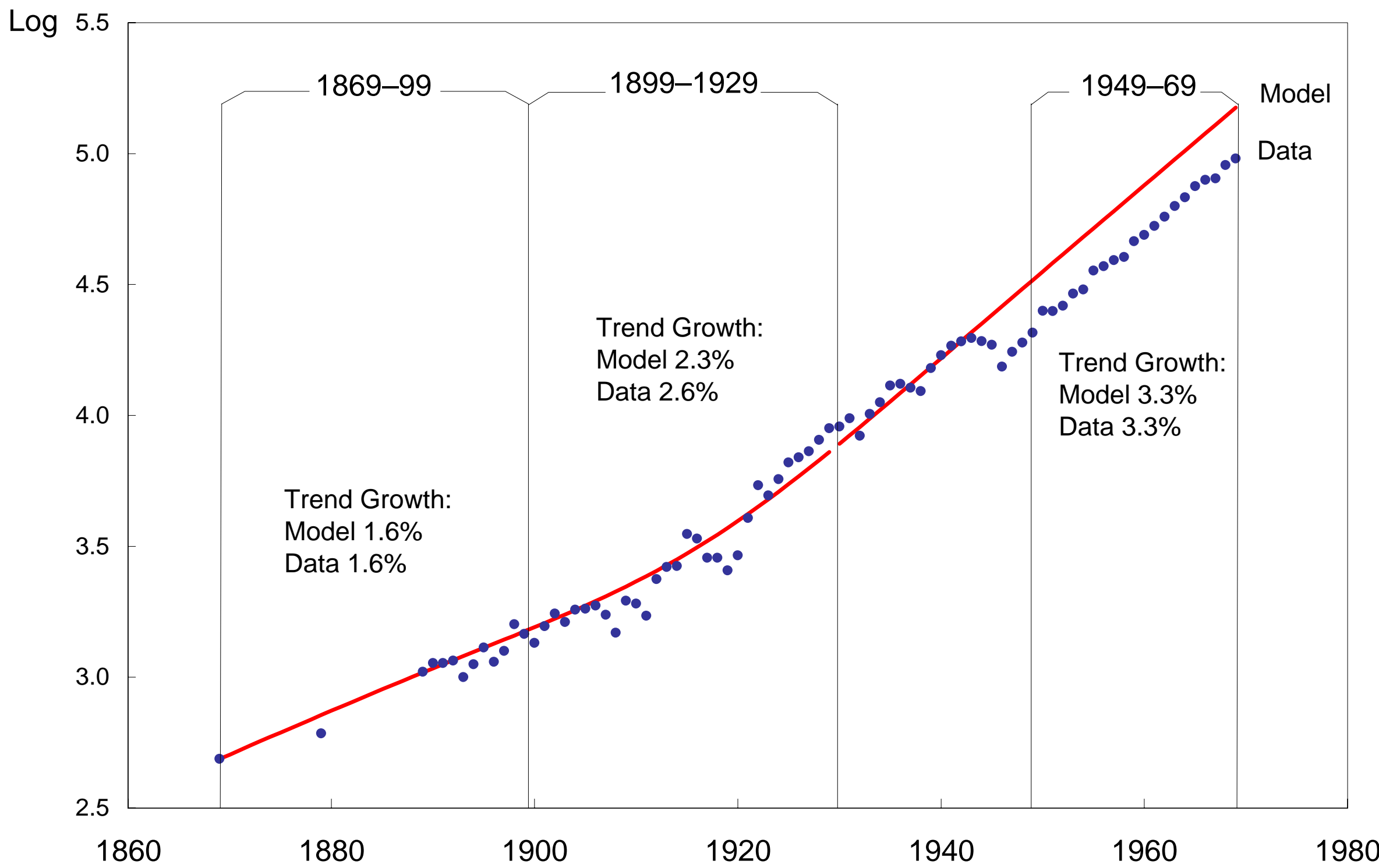




\section{Figure 6 ... A Slow Diffusion of New Technology ...}

Model's Predicted \% of Output Produced in Plants with New Blueprints (1869 or later)

vs. Actual \% of Horsepower Provided by Electric Motors in U.S. Manufacturing Plants, 1869-1939

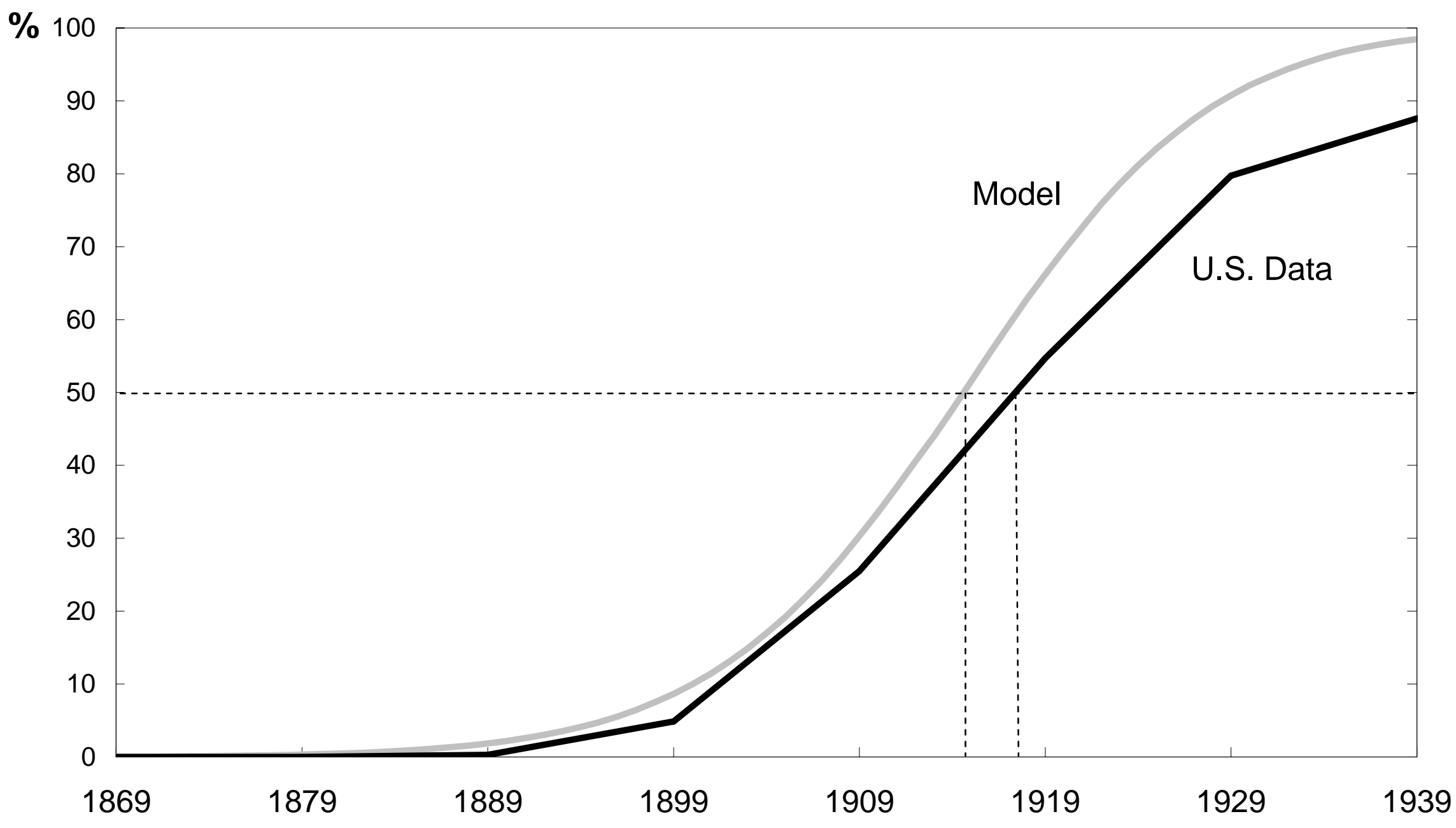




\section{Figure $7 \quad \ldots$ And Ongoing Investment in Old Technologies}

Model's Predicted \% of Output Produced in Plants with Blueprints Dated 1802-1869 (Steam) and Before 1802 (Water) vs. Actual \% of Horsepower Provided by Steam and Water Power in U.S. Manufacturing Plants, 1869-1939

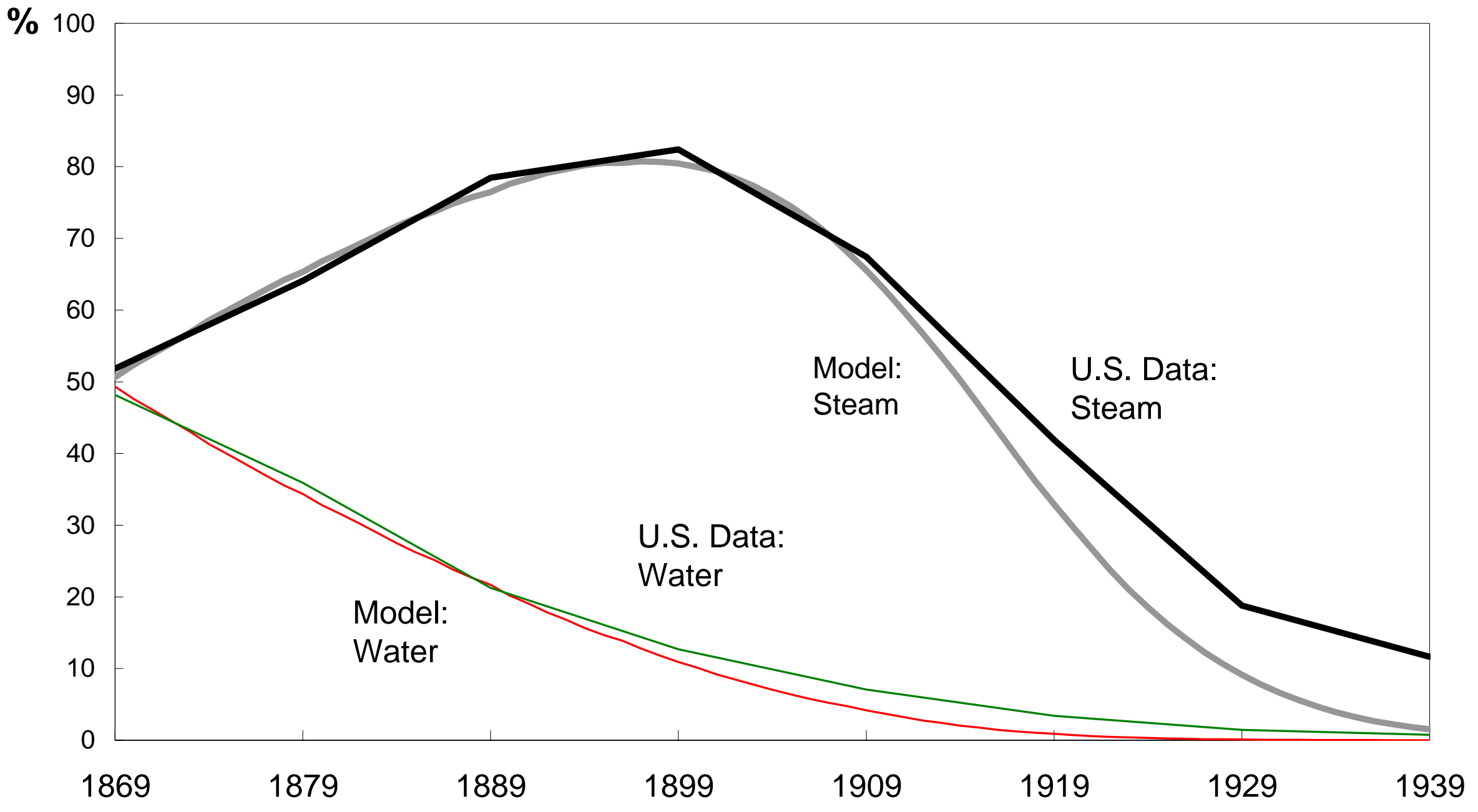


Figure 8 Initial Growth Rates Matter for ...

\section{A. ... The Speed of Transition ...}

Model's Predictions, with Various Initial Steady-State Growth Rates, for the Time

Until Productivity Growth Increases 1\% Point and the Time Until Diffusion Reaches 50\%






\section{B. ... And the Stock of Built-Up Knowledge}

Model's Predictions, with Various Initial Steady-State Growth Rates, for

the Amount of Built-Up Knowledge, $(\bar{A} / \tau)^{1-v}$, in the Old and New Steady States

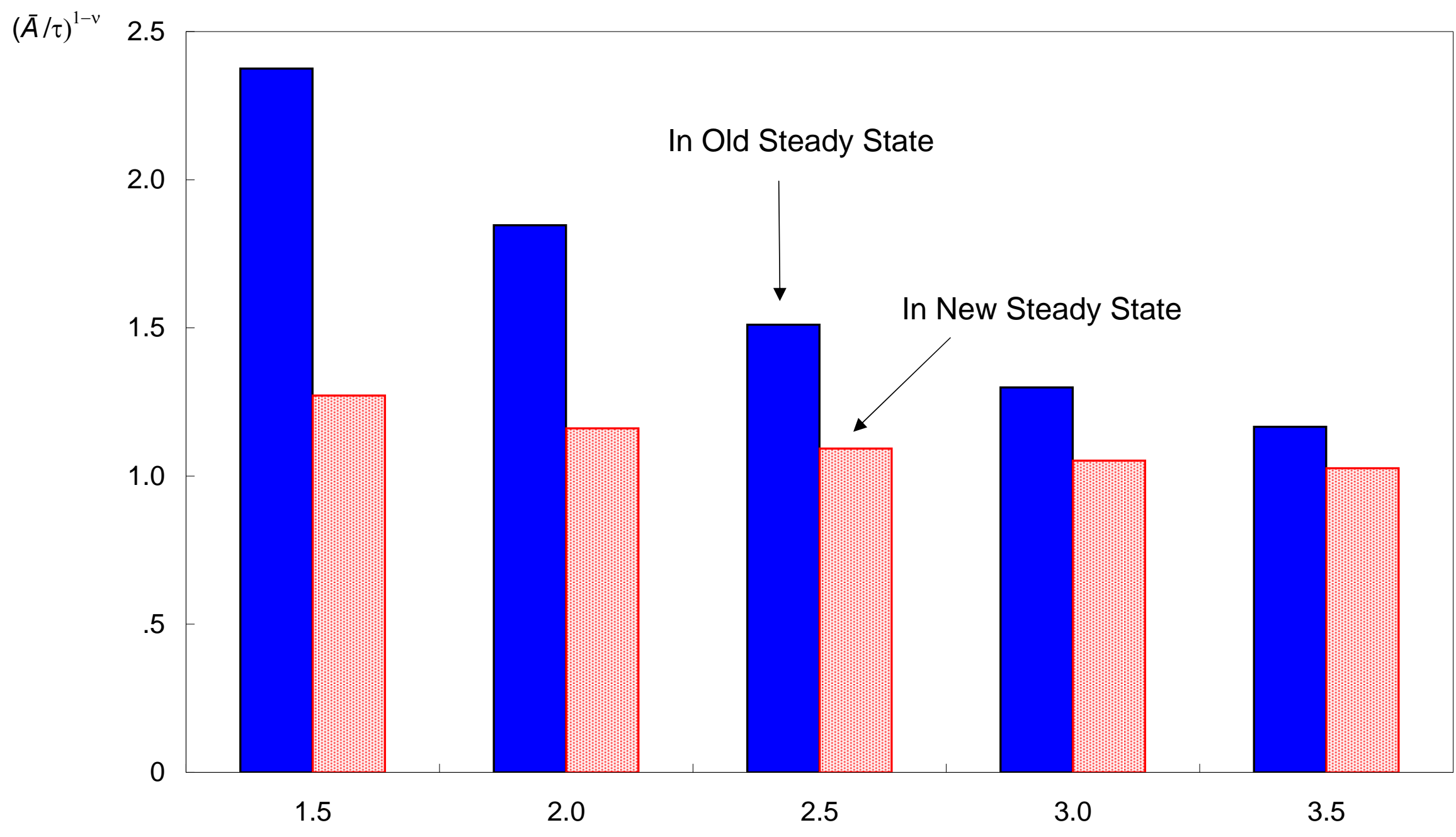

Growth Rate in the Old Economy (\%) 


\section{Figure 9 The Distribution of Employment With More Substantial Learning}

Cumulative Distribution of Employment by Age of Plants or Organizations

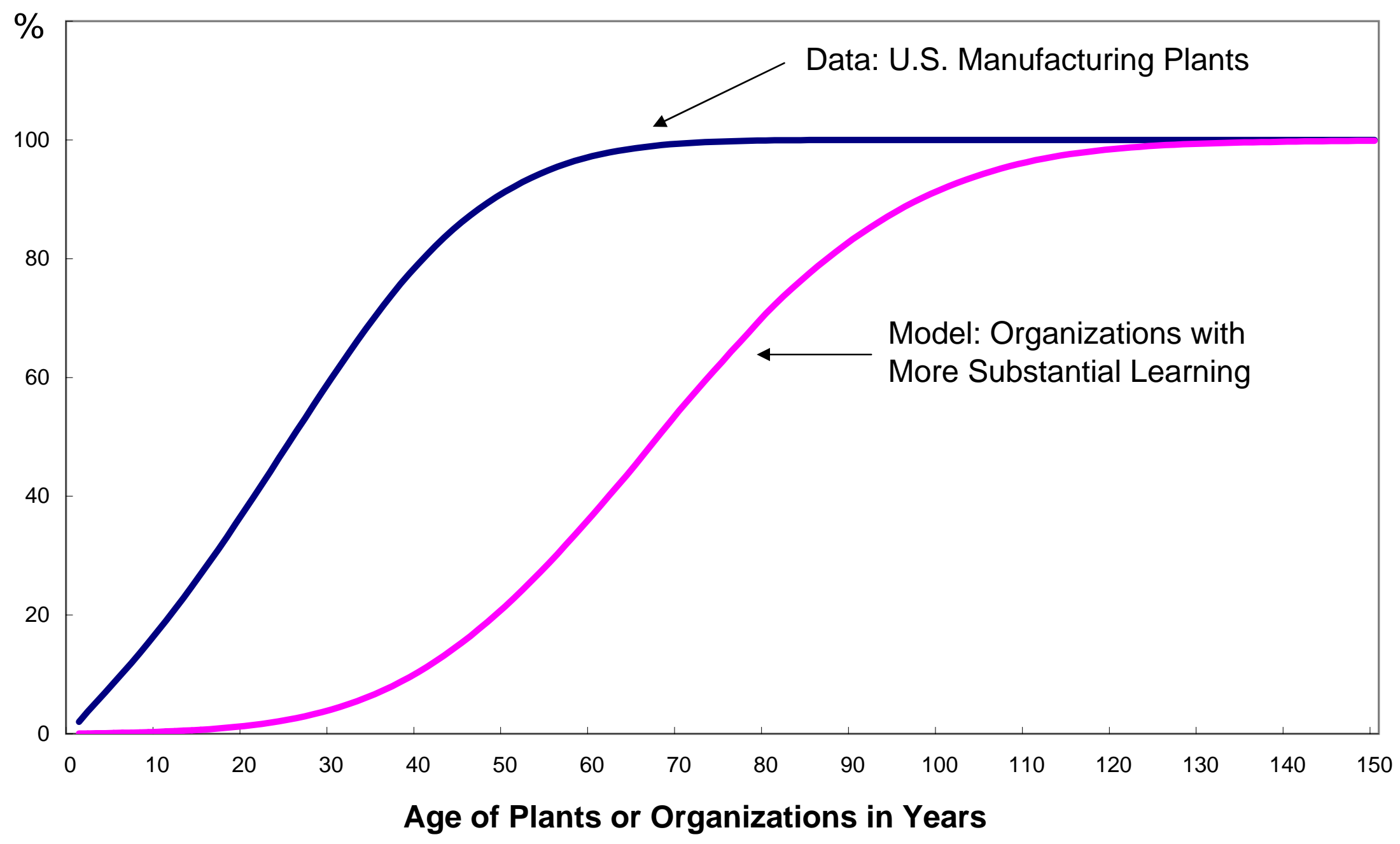

